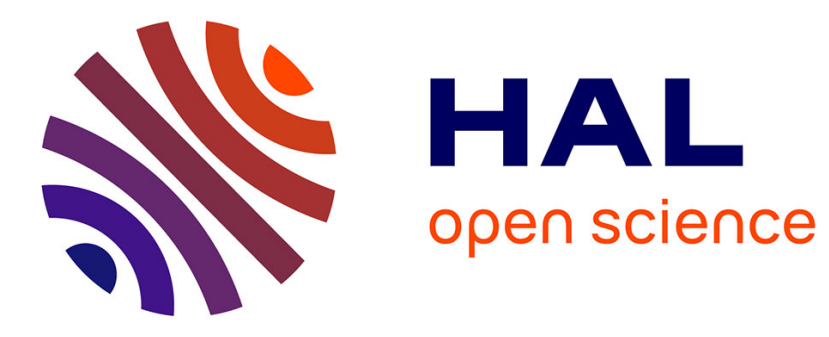

\title{
From 2D graphene nanosheets to 3D graphene-based macrostructures
}

Rabita Mohd Firdaus, Nawal Berrada, Alexandre Desforges, Abdul Rahman Mohamed, Brigitte Vigolo

\section{- To cite this version:}

Rabita Mohd Firdaus, Nawal Berrada, Alexandre Desforges, Abdul Rahman Mohamed, Brigitte Vigolo. From 2D graphene nanosheets to 3D graphene-based macrostructures. Chemistry - An Asian Journal, 2020, 10.1002/asia.202000747 . hal-02931579

\section{HAL Id: hal-02931579 https://hal.science/hal-02931579}

Submitted on 7 Sep 2020

HAL is a multi-disciplinary open access archive for the deposit and dissemination of scientific research documents, whether they are published or not. The documents may come from teaching and research institutions in France or abroad, or from public or private research centers.
L'archive ouverte pluridisciplinaire HAL, est destinée au dépôt et à la diffusion de documents scientifiques de niveau recherche, publiés ou non, émanant des établissements d'enseignement et de recherche français ou étrangers, des laboratoires publics ou privés. 


\section{CHEMISTRY - AN ASIAN JOURNAL}

https://doi.org/10.1002/asia.202000747

To be cited as: Chem. Asian J. 10.1002/asia.202000747

\section{From 2D graphene nanosheets to 3D graphene-based}

\section{macrostructures}

Rabita Mohd Firdaus ${ }^{[a] b]}$, Nawal Berrada ${ }^{[b]}$, Alexandre Desforges ${ }^{[b]}$, Abdul Rahman Mohamed ${ }^{*[a]}$ and Brigitte Vigolo*[b]

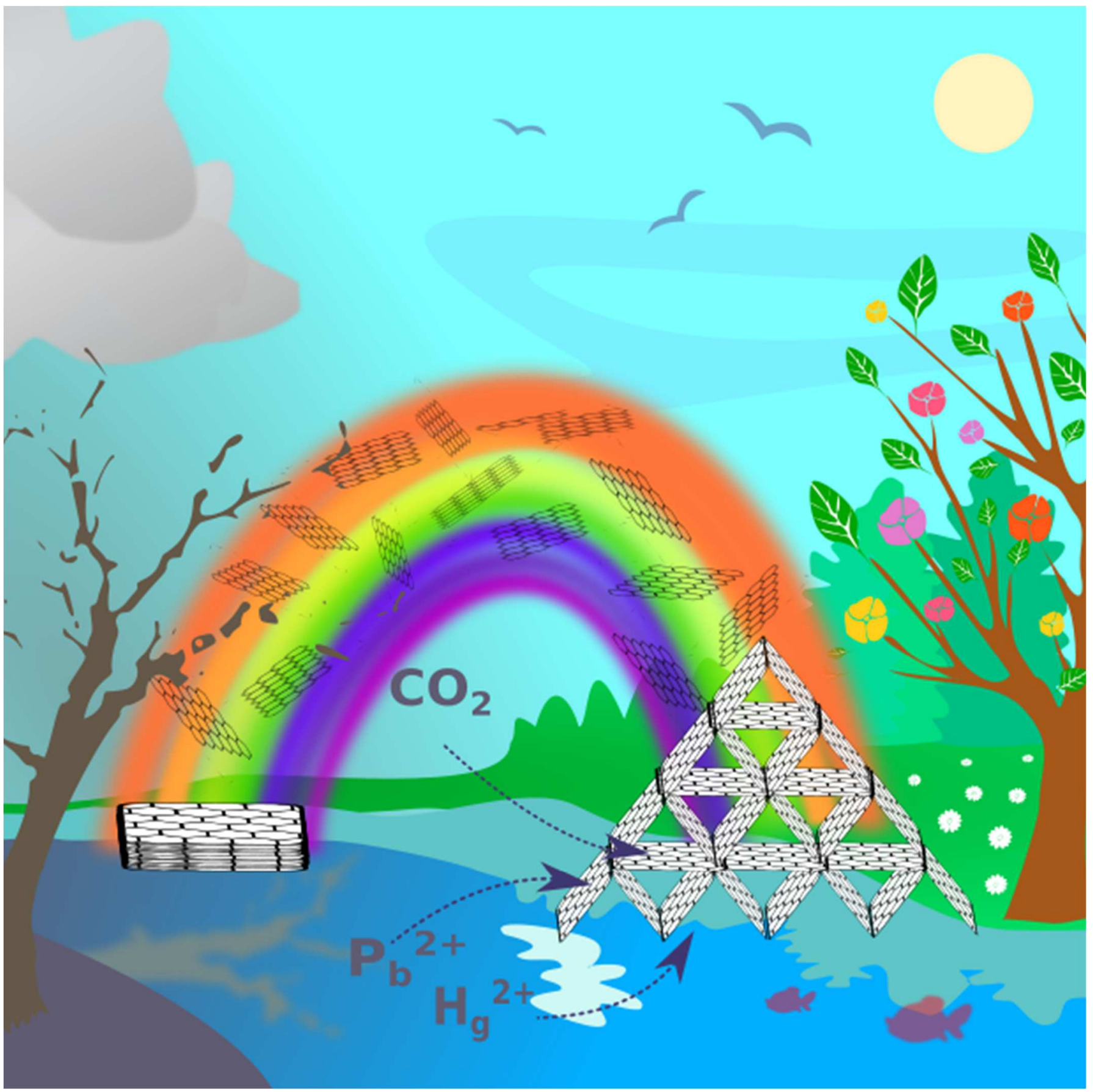


[a] [b] Rabita, MOHD FIRDAUS

School of Chemical Engineering,

Engineering Campus, Universiti Sains Malaysia

14300, Nibong Tebal, Seberang Perai Selatan, P. Pinang, (Malaysia)

E-mail : rabitafirdaus58@gmail.com

[b] Dr, Nawal BERRADA

Université de Lorraine, CNRS, IJL,

F-54000 Nancy, (France)

E-mail : n.berrada57@gmail.com

[b] Dr, Alexandre, DESFORGES

Université de Lorraine, CNRS, IJL,

F-54000 Nancy, (France)

E-mail : Alexandre.Desforges@univ-lorraine.fr

[b] Dr, Brigitte, VIGOLO (Corresponding Author)

Université de Lorraine, CNRS, IJL,

F-54000 Nancy, (France)

E-mail: brigitte.vigolo@univ-lorraine.fr

[a] Proffesor Dr, Abdul Rahman, MOHAMED (Corresponding Author)

School of Chemical Engineering,

Engineering Campus, Universiti Sains Malaysia

14300, Nibong Tebal, Seberang Perai Selatan, P. Pinang, (Malaysia)

E-mail:chrahman@usm.my

Abstract: The combination of exceptional functionalities offered by 3D graphene-based macrostructures (GBMs) has attracted tremendous interest. 2D graphene nanosheets have high chemical stability, high surface area and customizable porosity, which was extensively researched for a variety of applications including $\mathrm{CO}_{2}$ adsorption, water treatment, batteries, sensors, catalysis, etc. Recently, 3D GBMs have been successfully achieved through few approaches, including direct and non-direct self-assembly methods. In this review, the possible routes used to prepare both 2D graphene and interconnected 3D-GBMs were described and analyzed regarding the involved chemistry of each 2D/3D graphene system. Improvement of the accessible surface of 3D GBMs where the interface exchanges are occurring is of great importance. A better control of the chemical mechanisms involved in the self-assembly mechanism itself at the nanometer scale is certainly the key for a future research breakthrough regarding 3D GBMs.

\section{Introduction}

Carbon is a singular element of the Periodic Table since it plays a key role in nature. This atom is capable of forming several different structures called allotropes. These various forms of carbon have been found year after year. Several of them, such as graphite and diamond, have been found since ancient times; others were born at the end of the $20^{\text {th }}$ century, such as fullerenes (1985) and nanotubes (1991). A large number of scientists, including chemists and physicists, have worked on these different dimensional (D) materials: 3D for diamond and graphite ${ }^{1}, 0 D$ for fullerenes ${ }^{2}$, and $1 \mathrm{D}$ for carbon nanotubes (CNT) ${ }^{3}$, rendering them acquainted in a wide range of research fields.

In 2004, two scientists from Manchester University, A. Geim and K. Novoselov, made a serendipitous breakthrough, a discovery that will change the world in many ways. This amazing 2D-carbon substance is graphene, a single-atom thick layer of a hexagonal structure, $\mathrm{sp}^{2}$-bonded carbon atoms and until now, many have attempted to synthesize completely two-dimensional (2D) atomic crystal using an appropriate technique ${ }^{4}$. Due to its special and superior properties (mechanical, electrical, thermal, optical), graphene has become the main attraction among scientists for a number of years. Graphene is the thinnest, lightest $\left(1 \mathrm{~m}^{2}=0.77\right.$ $\mathrm{mg}{ }^{5}$ and hardest substance (between 100-300 times stronger than steel) as well as the best heat and electrical conductors with a thermal conductivity of $5 \mathrm{~kW} \cdot \mathrm{m}^{-1} \cdot \mathrm{K}^{-1}$ and an electron mobility of $15,000 \mathrm{~cm}^{2} \cdot \mathrm{V}^{-1} \cdot \mathrm{s}^{-1}$, respectively ${ }^{6,7}$. As part from exploiting the properties of 2D graphene nanosheets at the nanometer scale in electronics in particular, their assembly in hierarchized macroscopic structures or graphene-based macrostructures (GBMs) has grown of interest among the scholars in recent years. Since the $\mathrm{sp}^{2}$ carbon network can be functionalized in many manners, versatility of these GBMs in term of chemical affinity is a remarkable tool to control the interface interactions. For all these reasons, such substrates with smart surfaces are the focus of numerous studies in the scientific community.

Different strategies have been developed to create 3D nanostructures based on graphene called here GBMs. In fact, graphene can be seen as a bridge between the nanoscale and the bulk materials. Compared to a finely divided powder of graphene nanosheets, such hierarchical structured materials such as hydrogels, aerogels, foams or sponges are of great interest for a large number of applications. These latter are often related to the fields where surface and interfacial phenomena play a great role. Such nanostructured materials are especially desired in catalysis, energy and environmental applications because they can offer both high area and accessible surface.

Among the review papers already published and related to the 3D GBM topic these last 4 years, most of them are focused on particular fields of application. In 2017, M. Rethinasabapathy et al. ${ }^{8}$ and more recently, in 2019, the works from H. Wang et al. ${ }^{9}, \mathrm{~N}$. Youssefi et al. ${ }^{10}$ and Pang et al. ${ }^{11}$ evaluated the efficiency of 3D GBMs for water and/or air purification. 3D graphene-based aerogels were as well the subject of reviews focused on preparation of specific materials for batteries ${ }^{12}$, supercapacitors 
13 and energy storage ${ }^{14,15}$. General surveys related to 3D graphene-based materials are less commonly found in recent literature. We can mention the works from Bagoole et al. ${ }^{16}$, Gorgolis et al. ${ }^{17}$ and Yuan et al. ${ }^{18}$, all published in 2017. The present review aims at providing a recent critical analysis regarding on one hand, the methods of synthesis and the related properties of the produced 2D graphene nanosheets and on the other hand, the approaches to prepare GBMs. The present review is fully in line with the current attractiveness of these innovative graphene-based materials. Indeed, according to the years since the discovery of the "miracle material" as the first free-standing $2 \mathrm{D}$-crystal, the number of publications related to $2 \mathrm{D}$ and $3 \mathrm{D}$ graphene-based macrostructures has steadily increased (figure 1). As diverse sources of graphenic materials can now be provided by companies or easily produced in the laboratories in relatively big amount ( gram scale), the studies on GBMs mushroomed. The current challenge for the preparation of these materials hierarchized over several scales from nanometers to millimeters or even centimeters remains to successfully control the involved assembly mechanisms of the 2D graphene nanosheets.

Number of Publications

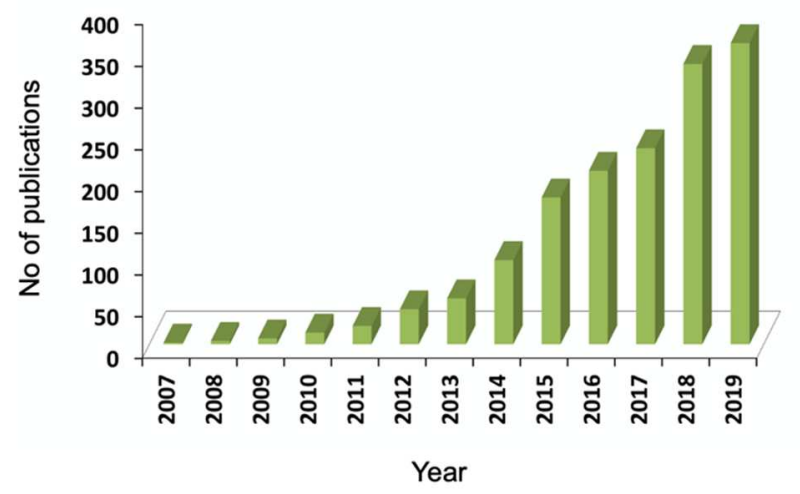

Figure 1 Number of publications from 2007 to 2019 on the topic of 2D and 3D graphene based from Web of Science.

Instead of focusing our review on one particular application, the chemical aspects which are of great importance to achieve a good control of the 3D GBM building mechanisms are especially discussed here. The term 'graphene' is widely used for different kinds of graphenic materials which are composed of a carbon network layers. However, depending on the synthesis method, the structural and chemical properties of $2 \mathrm{D}$ graphene are strongly different. These differences have especially important effects on the used method to prepare GBMs. Adding to the strategies to prepare GBMs, this review gives an overview of the different routes to prepare the $2 \mathrm{D}$ graphene, the building blocks of the $3 \mathrm{D}$ structured materials.

This review is organized in three main sections. The first one is focused on synthesis of 2D graphene nanosheets including both the bottom-up and the top-down approaches. The second one describes the strategies investigated to prepare 3D GBMs including direct methods such as Chemical Vapor Deposition (CVD) and non-direct approaches where 2D graphene is selfassembled by various routes: reduction of $\mathrm{GO}$ by electrochemical process, hydrothermal or solvothermal and modification of surface chemistry or addition of a cross-linker to induce bond creation between the graphene nanosheets. The discussion, in the third section, is conducted thanks to a property inevitably searched to be maximized: the surface area.

Rabita Mohd Firdaus received her MSc degree (2019) from Universiti Sains Malaysia (USM) Penang, Malaysia in chemical engineering. She is currently a cotutelle $\mathrm{PhD}$ student under the supervision of Prof. Abdul Rahman Mohamed and Dr. Brigitte Vigolo at Universiti Sains Malaysia (Penang, Malaysia) and Jean Lamour Institute, University of Lorraine (Nancy, France) respectively. Her main research interests are focused on developing and synthesizing 3D graphene-based material for environmental application.

Dr. Nawal Berrada completed her Master in 2016 after a project related to the recovery of precious metals from jewelry waste. She has also developed a green alternative method to clean jewels without cyanide-based chemicals under the supervision of Dr. E. Meux at University of Lorraine, France. She has completed her PhD in 2019 at the Institut Jean Lamour (University of Lorraine, CNRS, France) under the mentorship of Dr. A. Desforges and Dr. B. Vigolo. Her work was

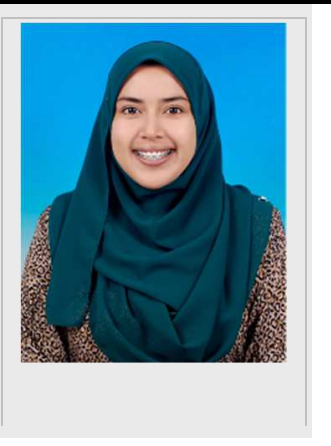
centered around developing chemical processes on carbon nanomaterials for the purpose of overcoming processing issues. Her activities were mainly devoted to carbon nanotubes and graphenic materials for their selective purification, surface modifications, dispersion and processing. She has developed efficient and innovative chemical treatments to CNTs.

After a Master in Chemical Physics, Dr. Alexandre Desforges completed his $\mathrm{PhD}$ on the preparation of polymer porous support from foams for catalysis applications (Université de Bordeaux, Bordeaux, France, 2004). He then completed a Postdoctoral research fellowship at Hull University (Hull, UK) on emulsions stabilized with both particles and surfactants. Since 2007, he is a lecturer at the university of Lorraine and working in the Institute Jean Lamour

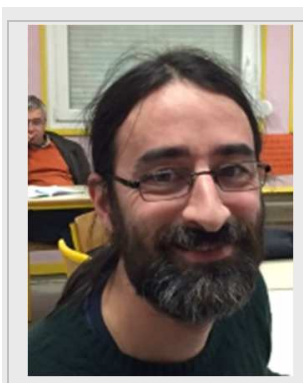
(Nancy, France). He has authored more than 25 papers in international peerreviewed journals. His research activities centre on chemicals modifications of interfaces, mostly on nanocarbons, with both fundamental and applied views. Applications are mostly focused on energy (fuel cells, thermal energy). 
Professor Ir. Dr. Abdul Rahman Mohamed is a lecturer of Chemical Engineering at USM since 1993. He received his $\mathrm{PhD}$ in Chemical Engineering from the University of New Hampshire, USA in 1993. His research interests span across the areas of reaction engineering, catalysis, air and water pollution, and nanotechnology. His collaboration with international researchers includes from Osaka University and Nagaoka University of Technology in Japan; and University of

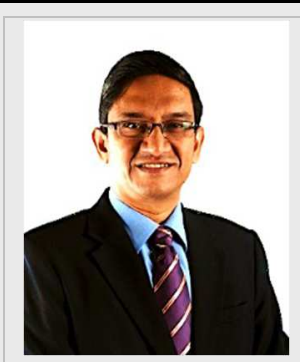

Lorraine, France has broadened his research influence. To date, he has published more than 400 research papers in international/national journals and conference proceedings with Scopus bibliographic $\mathrm{H}$-Index of 73 and total citation of more than 16,848 . As a result of his excellent research achievements, he has received more than 60 national/ international awards, honours and recognitions.

After a Master in Chemical Physics, Dr. Brigitte Vigolo completed her $\mathrm{PhD}$ on selfassembly of carbon nanotubes into macroscopic fibers (Université de Bordeaux Bordeaux, France, 2002). She then completed a Postdoctoral research fellowship at Complex Fluids Laboratory (Cranbury, New Jersey, USA) on nanostructured complex colloids from block-copolymer and multi-charged ions. Her second postdoctoral project was focused on CVD synthesis of carbon nanotubes for Field Emission Display in collaboration with the Thales Group company. Since 2004, she is a CNRS Researcher in the Institut Jean Lamour (Nancy, France). She has authored more than 60 papers in international peer-reviewed journals with a total of 2,700 citing articles and $\mathrm{H}$-index of 17 (source: Web of Science). Her research activities are dedicated to surface modifications of carbon nanotubes and graphene for the purpose of overcoming processing issues.

\section{2D graphene synthesis}

Graphene can be obtained by two main approaches: the bottom-up and the top-down. The bottom-up methods comprise the synthesis of graphene from alternative carbon sources either by CVD or epitaxial growth while the top-down methods involve the separation of stacked layers within graphite to yield graphene nanosheets, also called exfoliation. In the top-down methods, the intention is to induce an increase of the inter-layer spacing and exfoliate the graphene layers by means of mechanical and/or chemical forces. Figure 2 summarizes an overview of both the top-down and bottom-up approaches for 2D graphene synthesis with their characteristics, advantages and drawbacks that are discussed in this section.
These two techniques ultimately contribute to the framework of different types of graphene, including single layer graphene (SLG) ${ }^{19}$, few layer graphene (FLG) ${ }^{20}$, multilayer layer graphene (MLG) ${ }^{21}$, graphene oxide $(\mathrm{GO})^{22}$, graphene nanoplatelets (GNPs) ${ }^{23}$ etc. The structure, morphology, and properties of the resulting graphene, such as type of graphene, surface chemical properties, structural quality and also its physical properties are usually entirely dependent on the fabrication process. Bulk synthesis of graphene by CVD under specific conditions is becoming possible even if standard bottom-up methods are not often compatible with production of large quantities of graphene. The top-down methods can be used in the large-scale (several grams or more) synthesis. Some challenges including surface defects that arise during sheet separation and sheet re-agglomeration have to be considered for such approach. An important aspect regarding the characteristics of the produced graphene nanomaterials is their structural quality. Due to the presence of defects and the nature of the functional groups they bear, the chemical properties of the produced graphenic material can be significantly different. Whatever the synthesis method, graphene nanosheets are interesting nanomaterials since their nanoscale dimensions and high specific surface area (SSA) can be exploited for numerous fields of application. However, their physical properties, especially thermal and electrical conductivity strongly depend on the number of layers and the presence of defects in their structure. Few studies reported that various types of graphene with different number layers had unique properties in terms of electrical, mechanical or conductivity properties ${ }^{24-26}$. For example, Galindo et al. stated that the number of graphene layers had an effect on the electrical properties of thermoplastic polyurethane (TPU) as they found that SLG could have an electrical conductivity 10,000 times higher than that of FLG. Such high structural quality graphene with high conductivity is expected to be beneficial for most of applications. However, due to strong van der Waals interactions and $\pi-\pi$ stacking between graphene layers, these graphene materials may easily be restacked and aggregated which significantly affects the SSA, inhibits the mass transport rate of electrons which can limit its functions ${ }^{27}$.

There is also another common type of graphene material named GO. Typically, GO is a graphene-based material with numerous $\mathrm{O}$-containing groups bonded to its carbon atoms, including hydroxyl, epoxy, carboxy and carbonyl at the basal planes or edges ${ }^{28}$. The presence of these oxygen-containing functional groups distinguishes GO from other graphenes, as they might also affect electrical, electrochemical and mechanical properties. GO is classified as hydrophilic and negatively charged material allowing stable dispersion in water ${ }^{29}$. However, it may also show higher chemical performances compared to pristine graphene ${ }^{30}$. The characteristic of each graphene type depends on the synthesis method (and the related characteristics) and the methods further used for the 3D macrostructure preparation are also closely linked to the graphene type produced. This is the reason why it is important to know the principle and the respective properties of the graphene produced by each synthesis method. Another important aspect is that a large amount $2 \mathrm{D}$ graphene material is required to prepare GBMs. The commonly used methods to produce graphene are described below. 


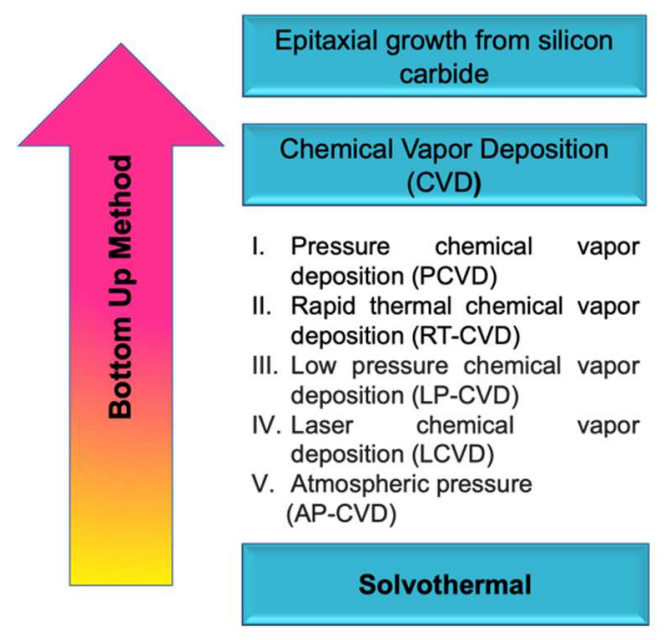

\begin{tabular}{l|l}
\hline $\begin{array}{l}\text { Type of graphene } \\
\text { produced }\end{array}$ & SLG, FLG, MLG \\
\hline $\begin{array}{l}\text { Amount of } \\
\text { graphene } \\
\text { produced }\end{array}$ & Wafer-scale \\
\hline Graphene quality & High \\
\hline Functionality & Indirect \\
\hline Precursor & $\begin{array}{l}\text { Carbon based precursor (solid, } \\
\text { liquid, gas) }\end{array}$ \\
\hline Advantages & $\begin{array}{l}\text { High transparency, high } \\
\text { conductivity, flexibility, }\end{array}$ \\
\hline Drawbacks & $\begin{array}{l}\text { High cost, required high } \\
\text { temperature }\end{array}$ \\
\hline
\end{tabular}

\section{Mechanical Exfoliation}

I. Scotch tape method

II. Ball milling method

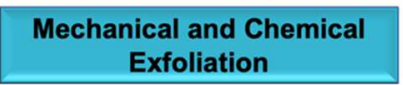

I. Sonication method

II. High- shear mixing method

III. Microfluidization method

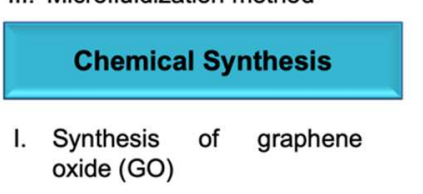

\begin{tabular}{l|l}
\hline $\begin{array}{l}\text { Type of graphene } \\
\text { produced }\end{array}$ & GO, GNPs \\
\hline $\begin{array}{l}\text { Amount of } \\
\text { graphene } \\
\text { produced }\end{array}$ & Macroscopic amount \\
\hline Graphene quality & High to low \\
\hline Functionality & Direct during synthesis \\
\hline Precursor & Graphite \\
\hline Advantages & $\begin{array}{l}\text { Low cost, high productivity, easy } \\
\text { dispersion }\end{array}$ \\
\hline Drawbacks & Hard to control the size \\
\hline
\end{tabular}

Figure 2 Schematic of top-down and bottom-up approaches for 2D graphene synthesis.

\subsection{D graphene synthesized by bottom-up methods}

For bottom-up methods, graphene is synthesized from a carboncontaining precursor after its decomposition and covalent bonds between carbon atoms are created onto a catalyst leading to the well-known honeycomb $\mathrm{sp}^{2}$ carbon network of the grown graphene ${ }^{23}$.

Epitaxial growth from silicon carbide. Accidentally discovered by Berzelius in 1824 during the experience of diamond synthesis, silicon carbide ( $\mathrm{SiC})$ has been the focus of several studies since the $19^{\text {th }}$ century. Norimatsu and Kusunoki illustrated the basic concept of graphene growth using thermal decomposition of $\mathrm{SiC}^{31}$. In this technique, they clarified that only the silicon atoms left on the substrate when SiC was heated either in a vacuum or in an argon environment due to the disparity between silicon and carbon vapor pressure, and the remaining carbon atoms randomly formed epitaxial graphene on the substrate. As a result, high-quality and homogeneous graphene with a well-ordered number of layers at the wafer scale can be generated directly on the semi-isolating substrate. According to Edwards et al. in epitaxial production, the quality of graphene generated may be high but rarely $\leq 2$ layers and may also be transferred from SiC substrates. However, while SiC substrates are commercially available, they are still too expensive for commercial applications ${ }^{32}$.

Standard wafer-scale synthesis of graphene by CVD. CVD is a widely used method for graphene synthesis which requires an accurate control of the synthesis conditions including temperature, pressure, deposition time, type of precursor ${ }^{22}$. First, the used precursor gas decomposes on a metallic (usually $\mathrm{Ni}$ or $\mathrm{Cu}$ ) film deposited on a $\mathrm{SiO}_{2}$ substrate. The second stage is the formation of the carbon structure of (single, double or multilayer) graphene in a relatively well controlled manner using the dissociated atoms at temperature below $1000^{\circ} \mathrm{C}{ }^{33}$. This is an interesting process since it allows to prepare of high-quality graphene with a controlled number of layers.

Large-scale synthesis of graphene by CVD. Polsen et al. presented the development of high-speed roll-to-roll manufacturing graphene using a concentric tube CVD reactor suitable for continuous production of graphene ${ }^{34}$. In a concentrated tube, the substrate was continuously transformed into a helical direction and they found that the connection between the process velocity and the characteristics of graphene produced 
on Cu foil were correlated. High-quality SLG was formed at lower speeds while the rapid nucleation of small graphene domains was observed at higher speeds. In addition, Lee and coworker reported a study on synthesizing high-quality graphene by the CVD of liquefied petroleum gas (LPG) and LPG- $\mathrm{H}_{2}$ over $\mathrm{Cu}$ foil at $1000{ }^{\circ} \mathrm{C}{ }^{35}$. From the findings, they agreed that the rate of graphene growth utilizing LPG was 10 times faster compared to traditional methane-based synthesis, which provided potential to get one step closer to large-scale commercial graphene application. Under current conditions, FLG obtained at growth time $1 \mathrm{~min}$ was found to be very effectively as it successfully covered the entire $\mathrm{Cu}$ surface. Polat et al. demonstrated an interesting low-cost route to acquire large-scale and high-quality graphene films with the ultra-smooth copper foils ${ }^{36}$. In their twostep process, methane was first sent to the growth chamber at $1035^{\circ} \mathrm{C}$ in corporation with hydrogen flow and they later used a photoresist (PR) drop casting method for the transfer of graphene layers to the rigid substrates. In terms of electronic transport properties, they compared ultra-smooth copper foils with standard copper foils and found that a more effective transmission modulation up to two times (at $700 \mathrm{~nm}$ ) was achieved by using smooth Cu-graphene in supercapacitors acting as optical modulators. Similarly, Dayou et al. produced large-scale graphene by a simple CVD approach using copper impregnated on $\mathrm{MgO}$ powder as catalyst ${ }^{37}$. Besides, the graphene was easily grown on the catalyst without any reduction step before the growth stage. Based on the findings, they found that the graphene samples produced mainly contained of carbon (>90\%) and they emphasized that using their approach, graphene could be manufactured at lower cost with high production efficiency and growth rate.

Large-scale synthesis of graphene by solvothermal. In 2008, Choucair et al. have found that graphene could be synthesized via a sodium and ethanol low-temperature flash pyrolysis ${ }^{38}$. They performed the experimental work in a two-step procedure which was first a reaction in a closed Teflon reactor under solvothermal conditions followed by a pyrolysis of the intermediate compound. The graphene produced had significant SSA of up to $612 \mathrm{~m}^{2} \mathrm{~g}^{-1}$. The authors stated that the obtained graphene material could facilitate reinforcement of composites, their incorporation in electronic devices, batteries, sensors, fuel cells and their use for catalysis. These solvothermal reaction conditions are important in order to produce a large-scale and low-cost graphene. Wang et al. published a novel carbon nanosheet (CNS) bottom-up solvothermal synthesis using simple, inexpensive chemical reagents such as glycerol, concentrated sulfuric acid and melamine and they found that melamine played a significant role in the development of a layered sheet structure among the chemical reagents ${ }^{39}$. Additionally, the CNS served as a highly effective and efficient adsorption agent with certain benefits such as high yield, low cost, and fast processing time. Generally, each method that is typically included in the bottom-up approach has its own advantages and disadvantages. Currently, graphene from $\mathrm{SiC}$ and metallic films is not produced in sufficient quantity to prepare GBMs. Novel CVD and solvothermal approaches are developing to produce graphene nanostructures with large quantities. However, these approaches remain tricky, time consuming and of high production cost. And, to the best of our knowledge, in the literature, these $2 \mathrm{D}$ graphene materials were not used to produce GBMs so far. The top down methods, described in the following, are currently the preferred graphene synthesis approaches to prepare the starting $2 \mathrm{D}$ materials for GBMs.

\subsection{D graphene synthesized by top-down methods}

The top-down approach is fundamentally based on the principle of bulky materials (here graphite) that are broken down to generate nano-sized particles (here graphene nanosheets) with the aid of an energy source whether in the mechanical, chemical or thermal energy form, which can also be combined. Graphite is a cheap material and the amount of the prepared 2D graphene (up to several grams) is often by far higher than that produced by the CVD methods. And the interest of these topdown methods is indisputable for the 3D GBMs. The reported methods for graphenic material synthesis by the top-down approaches are described below.

Mechanical exfoliation. There are three common procedures used for the mechanical exfoliation of graphite depending on the direction of the applied forces (normal force, lateral force and no direction) to break the van der Waals bonds in between the graphene layers within graphite. The mechanical exfoliation technique for graphene synthesis is regarded as a strategy with both minimum chemical products use and good process control. Figure 3 gives a schematic diagram of the general mechanical processes involved in exfoliating graphite.

(a) Normal force
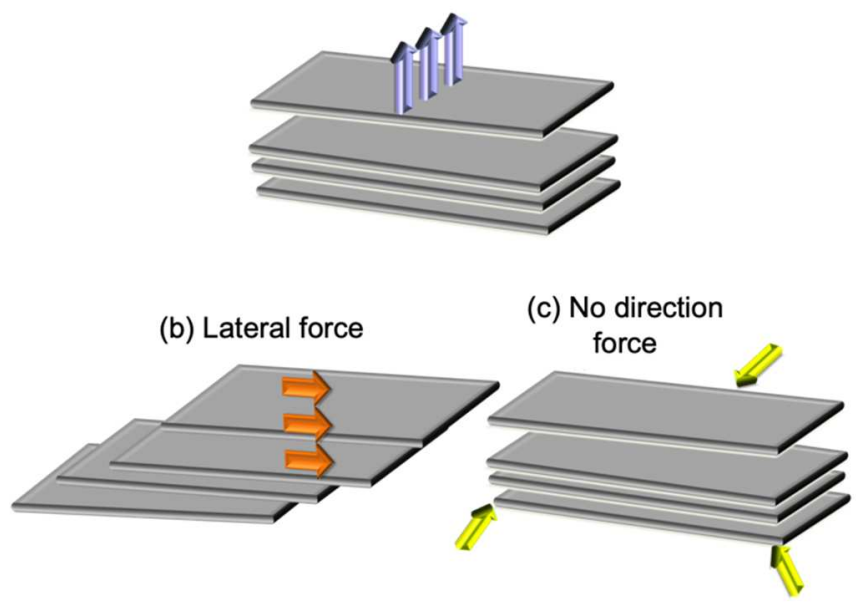

Figure 3 Schematic diagram of mechanical routes (a) normal force (b) lateral force (c) no direction force for exfoliating graphite.

The widely known Scotch Tape method uses the mechanism of normal forces where the graphite layers are peeled apart to counteract the attraction of van der Waals. In fact, the graphite self-lubrication capacity in the lateral direction allows the lateral forces to be introduced to facilitate electrostatic repulsion between two layers. Lu et al. experimented using Highly Oriented Pyrolytic Graphite (HOPG) and they succeeded in obtaining multiple-layer tick pieces of graphite. In this procedure, the HOPG samples are splitted into small pieces and the $\mathrm{SiO}_{2}$ film was deposited on a freshly cut layer of HOPG substrate with plasma enhanced CVD (PECVD). In particular, the $\mathrm{SiO}_{2}$ film plays an important role in electronic and photoelectronic industries. And the development of hybrid graphene-Si structures/devices may offer a seamless integration of graphene into current microelectronics technology ${ }^{40}$. Instead, in 2004, the Manchester team used the process of successive peeling, commonly known as 'Scotch Tape', to first create FLG films up to $10 \mu \mathrm{m}$ in lateral size $^{7}$. Researchers from the same group isolated the individual 
atomic layer of graphene by a cleavage of heavily structured materials ${ }^{41}$. They have shown that the 2D-crystals gained were stable at room temperature. However, despite its simplicity, this method is not suitable for large-scale production of graphene, especially due to its low yield. Recently, there is another mechanical exfoliation method used by a number of graphene development scientists, known as ball milling, for the scalable preparation of high-quality of pristine / functionalize graphene. Generally, this process involves crushing of graphite microstructures into graphene flakes (GFs) through attrition of metal balls onto graphite microstructures in a revolving hollow tubular shell and usually the average size of the GFs obtained depends on the milling parameters, including ball-to-graphite ratio, initial graphite weight, milling rate and milling revolution per minute (rpm) ${ }^{42}$. For example, Lv set up a stainless steel jar mill using melamine as an experimental milling agent $\left(\mathrm{Na}_{2} \mathrm{SO}_{4}\right)$ at 150 rpm and for $24 \mathrm{~h}$, and noticed that the size of the graphene nanosheets produced was approximately to hundreds of square nanometers ${ }^{43}$. By having a similar approach, Alinejad and Mahmoodi have synthesized GFs using a planetary ball-mill and zirconia balls with sodium chloride $(\mathrm{NaCl})$ as a milling agent (experimental condition: $350 \mathrm{rpm}$ for $2 \mathrm{~h}$ with $0.4 \mathrm{MPa}$ of $\mathrm{Ar})^{44}$. The transmission electron microscopy (TEM) results showed the size of GF obtained was $50 \times 200 \mathrm{~nm}^{2}$ and they reported, with the support of $\mathrm{NaCl}$ particles, graphite was broken into smaller pieces and particle agglomeration was avoided. Recently, a study was carried out using a wet milling process that used $\mathrm{N}$ methylpyrrolidone (NMP) milling container as a surfactant with a rate of $500 \mathrm{rpm}$ for $10 \mathrm{~h}^{45}$. As a result, a large-scale production of MLG was achieved at a rate of $0.0085 \mathrm{mg} \mathrm{mL}^{-1} \mathrm{~h}^{-1}$ with a good structural quality. Cheng at al. has discovered a significant improvement for the scalable production of surface-functionalize GNPs by ball milling of graphite in the presence of aryl diazonium chloride ${ }^{46}$. This approach is designed to be a sustainable solution as it is a low-cost, high-yield and industrially friendly technique. From the work, they successfully maintained the chemical properties of graphene platelet materials, as they have observed that the graphene platelets contain low level of structural defects and oxygen in their basal planes. In parallel, the produced graphene platelets showed benefits for the simple reinstatement of the $\pi$-conjugated structure at high temperatures along with structural stability at low temperatures. Likewise, with a low-cost and high-yield production, researchers have introduced a potential solution to the large-scale manufacturing of edgecarboxylated GNPs by facile graphite ball milling 47,48 . Basically, the principle of the edge-selective functionalization in the ballmilling process could occur by the reaction between reactive carbon species induced by mechanochemical cleavage of graphitic $\mathrm{C}-\mathrm{C}$ bonds and gases incorporated into a sealed ballmill crusher. The unreacted latent activated carbon particles in the crusher may be removed by subsequent oxidation of air exposure resulting in the introduction of other oxygenated groups such as hydroxyl and carboxyl at broken edges only ${ }^{49}$. Ball milling technique can produce good quality graphene in large-scale production, yet it requires an additional purification step after finalization of the milling process to remove the used solvent.

Combination of mechanical and chemical exfoliation. Apart from the development of exfoliation by means of a mechanical strategy, researchers have also combined the mechanical exfoliation with the effect of chemicals, such approach is known as liquid phase exfoliation (LPE). Basically, the used solvents 50,51 , polymers ${ }^{52-54}$ and surfactants 51,55 promote the exfoliation process and allow the formation of uniform graphene dispersion. LPE mainly consists of two different graphite exfoliation processes, which either by sonication or shearing forces in a high shear mixture. Recently, another technique known as microfluidization has been shown to be efficient in exfoliating graphite with appropriate aqueous solvent and high shear rate ${ }^{56,57}$.

Sonication. Sonication is a powerful tool for the exfoliation of a material which normally starts from bulk solid using a bath or tip sonicator. This method is widely used as it is simple and practical. However, the major problem was that the graphene generated was extremely low in concentration in the used solvent. Thus, in order to overcome this issue, the process was improved. Kairi et al. pointed out that, in order to have the appropriate surface energy that is well suited for graphite, the selection of solvent used was important as it could facilitate the exfoliation process ${ }^{42}$. For example, Bhoria carried out a study using few solvents such as cyclohexanone (CYN), sodium citrate (SC), dimethyl sulfoxide (DMSO) and NMP together with additives like phenolphthalein and anthracene in LPE system ${ }^{58}$. From this work, it was found that the organic solvent with additives played a significant role in increasing the concentration of exfoliated graphene in the solvent. In addition, there are also several aspects which could be considered to enhance the concentration of graphene, e.g. expanding the sonication time, raising the original concentration of graphite, introducing polymers, etc. In order to avoid graphene restacking during exfoliation, researchers have found that, with the aid of surfactants or dispersing agents, graphene sheets can be maintain in a good dispersion state after sonication ${ }^{59-61}$.

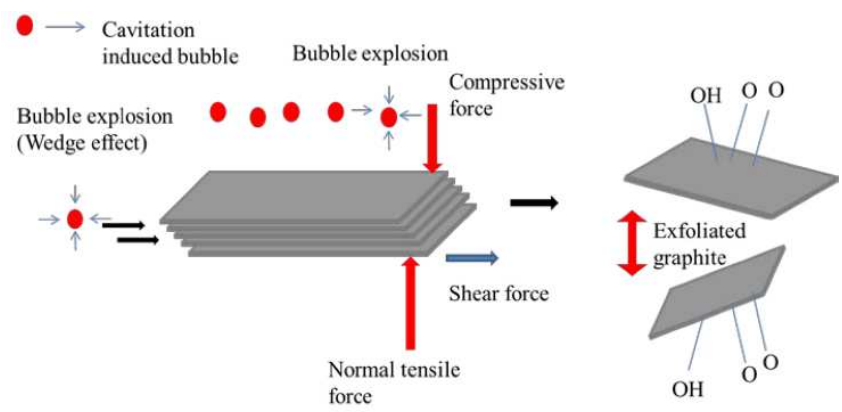

Figure 4 Illustration of the possible mechanism of graphite exfoliation. Reproduced with permission from Ref. ${ }^{62}$, Open Access, MDPI.

Lin et al. have reported a facile and environmentally friendly approach with a stable dispersion of MLG using the OzoneAssisted Sonication technique ${ }^{62}$. They proposed the possible mechanism of graphite exfoliation where the development and collapsing of microbubbles in liquids were attributed to cavitationinduced pressure vibrations (Figure 4). Principally, during the sonication phase, pressure fluctuation occurred due to ultrasonic waves scattered over the graphite suspension, creating small vacuum bubbles. So, in low-pressure phases, small vacuum bubbles tended to absorb energy, while in high-pressure phases, they intensely collapsed. Basically, in this method, the cavitation and shear forces have a major role in the exfoliation of graphite to produce graphene.

High shear mixing method. As known, the graphite exfoliation that includes shear and high shear mixing as part of the procedure has been commonly used up to the present day. 
However, in both situations, intercalation might increase the layered crystal and substantially weaken the interlayer binding forces. Indeed, as reported, these approaches give very small quantities of graphene and limit scale-up potentials ${ }^{63}$. In this section we addressed the graphite high shear exfoliation method for the development of graphene, which is more reliable and can be increased to an industrial level. LPE of 2D materials with the use of high shear mixing has been acknowledged for some time and can be extended to a variety of materials, including graphene 64-66. In fact, this approach is also regarded as a basic procedure with scalable methods for producing high-quantity graphene. In order to achieve high yield exfoliation, mixers with spinning blades were used for the creation of high shear rates in solvents containing bulk graphite. Varrla et al. reported a method for producing large quantities of free defect graphene using a highshear mixing method using a kitchen blender and household detergent ${ }^{64}$.

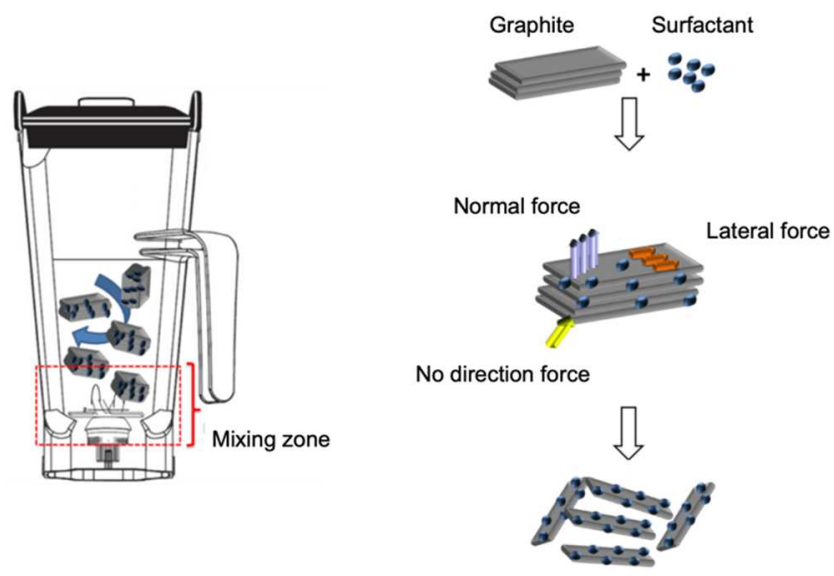

Figure 5 Schematic diagram of possible high shear mixing mechanism.

The main factors contributing to the scale up production of graphene were the initial graphite concentration, surfactant concentration, mixing volume, mixing time and speed of spinning blade. Based on the Raman results, the calculated ratio of $I_{D} / l_{G}-$ ratio between the area/height of the $D$ band, related to present defects in graphene structure, and that of the $\mathrm{G}$ band, related to the intrinsic vibrational modes of the $\mathrm{C}=\mathrm{C}$ bonds of the $\mathrm{sp}^{2}$ network- was always in the range of 0.3 to 0.7 and this showed that shear exfoliation using the rotating-blade mixer did not significantly introduce defects to the basal plane of the produced graphene. Besides, the results showed the concentration of exfoliated graphene was significantly increased with time, resulting in a time-independent production rate. Basically, the presence of surfactant is essential to support the reduction of water surface tension. During the exfoliation of graphite, high shear forces are mainly localized in the mixing zone and exfoliation mostly occurs in this area (Figure 5). Also, the lateral force becomes predominant in the exfoliation process and plays a major role, while the normal and non-directional force gives a significant effect on the bending, splitting and fracturing of the graphite sheets. In addition, the impact of collisions also promotes an efficient exfoliation process ${ }^{67}$.

Microfluidization. Microfluidization is known as an advanced technique in LPE because it uses high-pressure homogenization technique; where high pressure is exerted to the fluid and the pressure force drives the fluid to pass through the microchannels. Besides, using this technique, it helps to reduce the formation of defects as it provides mild exfoliation conditions during the process. Wang et al. demonstrated the exfoliation of pristine graphite in water/surfactant by using a lab-scale homogenized pressure ${ }^{56}$. The proposed surfactants were sodium dodecyl sulfate (SDS), Tween 80 (TW80) and Pluronic F127 (F127). In this study, a mixture of graphite, water and surfactant was pressurized and sent to the microchannel during the microfluidization process, resulting in cavitation, viscous shear forces, release of pressure and graphite collisions. Besides, the cavitation caused the bubbles to disintegrate around the graphite flakes, allowing microjets and shock waves to act decisively onto the graphite surfaces. The Raman analysis showed that the $I_{D} / I_{G}$ value shifts after 30 cycles from $\sim 0.03$ for graphite to $\sim 0.56$ for graphene flakes, which resulted in minimal structural defects. Similarly, Karagiannidis et al. had established a practical method of exfoliating natural graphite powder using a sonication and microfluidization series in a mixture of NMP and sodium hydroxide $(\mathrm{NaOH})$. Basically, the sonication step created a cavitation in fluids which triggered the turbostatic structure of graphite and as the result, the distance between layers increased which weakened the strength of van der Waals forces ${ }^{57}$. According to $\mathrm{Yi}$ and Shen, with longer duration or high-intensity sonication, solvents could endure from degradation ${ }^{68}$. Microfluidization treatment has therefore been adopted to promote exfoliation performance.

Chemical exfoliation. GO is a widely known form of among graphene-based materials. It is a graphene nanosheet of usually around 2-5 layers bearing a lot of oxygen-containing groups ${ }^{69}$. Its attractiveness comes from its possible synthesis in large volume with a quite simple method. Another advantage of GO compared to high-quality graphene, leading to its great interest for 3D GBMs, is its good dispersibility in water thanks to these surface functional groups. Basically, there are multiple routes for preparing GO including the Staudenmaier ${ }^{70}$, Brodie ${ }^{71}$ and Hummers and Offeman methods ${ }^{72}$. Depending on the used approach, different possible structure of $\mathrm{GO}$ might be formed depending on the oxidation conditions. The GO structure models, for example proposed by Hummers and Offeman ${ }^{72}$, show that GO bears different oxygenated $\mathrm{sp}^{3}$-hybridized carbon functional groups and also lightly functionalized zones where there are pre-dominantly $\mathrm{sp}^{2}$-hybridized carbon (graphene-like) atoms. Figure 6 illustrates the most proposed model that summarizes the typical functionalities of $\mathrm{GO}^{73}$. Among the possible functional groups, hydroxyl and epoxide are proposed to decorate the basal plane which are segregated into islands among the lightly oxidized graphene-like regions. Carboxylic acids or carboxylates, depending on the $\mathrm{pH}$ of the solution, are more present on the edges of the sheets ${ }^{74}$.

Chemical reduction of GO has gained a great deal of attention owing to its simple procedure, cheap and easy accessibility of materials. Typically, this approach requires the alteration of GO with certain functional groups, such as carboxyl, hydroxyl and epoxy groups, and the reduction of GO through specific reduction processes ${ }^{75}$. In a most of cases, the chemical reduction of GO is conducted using hydrazine $\left(\mathrm{N}_{2} \mathrm{H}_{4}\right)$, hydrazine hydrate, sodium borohydride $\left(\mathrm{NaBH}_{4}\right)$, metals, redox active sulfur species, reductive acids, enzymatic reduction etc. ${ }^{76}$. Less toxic reducing agents such as ascorbic acid (Vitamin C) are also efficient to reduce GO. Very recently, Rattan et al. came out with fascinating routes that are very economical and environmentally friendly, 
where reduced GO or rGO was prepared by using fresh ginger and garlic extracts ${ }^{77}$. We will see later in this review that reduction of $\mathrm{GO}$ is also widely used as a one-pot approach to prepare 3D GBMs from GO; reduction of $\mathrm{GO}$ and bonds being created in one process

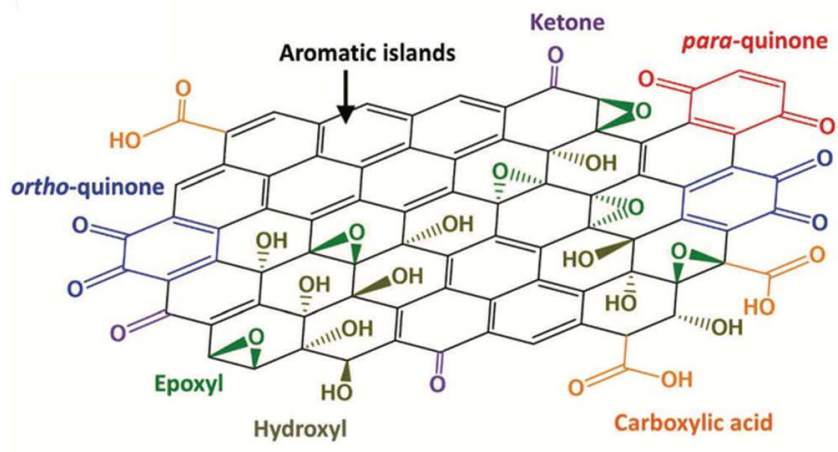

Figure 6 General model of GO demonstrating various oxygen functional group types distributed across aromatic regions. Reproduced with permission from Ref. ${ }^{73}$, Copyright The Royal Society of Chemistry 2018.

\section{2D graphene nanosheets to 3D GBMs}

Extensive research has been centered around the preparation of $3 D$ structures of graphene, such as 3D GBMs, sponges or aerogels (GAs). For that purpose, two main routes are usually investigated. For the direct synthesis of 3D GBMs, graphene is usually grown by CVD consists on a template containing the catalyst. Otherwise, already produced graphene nanosheets can be assembled to form 3D GBMs by non-direct approaches. For these latter, GO is widely used as the graphene precursor thanks to its high dispersion ability in aqueous media, functionality and stability ${ }^{78,79}$. GO is very effective as a starting material for synthesizing of GBMs due to the presence of oxygen moieties on both basal plane and edges ${ }^{80}$ making them capable of reacting covalently with different compounds and thus generating new materials with properties adaptable to specific applications. If superior physical properties are required, non-GO-graphene such as SLG, FLG, MLG, GNPs, GF... are preferentially used as the starting material for $3 D$ assembly of graphene. These graphene kinds are highly hydrophobic, and they have a strong tendency to restack through van der Waals forces, which leads to the low surface area, electrical and mechanical performances that adversely affect the use of graphene in some applications. One approach to address this constraint is to introduce functional groups to these $2 \mathrm{D}$ graphene materials before the assembly stage. Self-assembly due to induced attractive forces can occur due to hydrophobic interactions and $\pi-\pi$ stacking between the reduced nanosheets of GO for example. However, the subsequent graphene-based material suffers of low mechanical resistance. Thus, procedures inducing strong covalent bonds between the graphene nanosheets within the 3D structure allowing to improve mechanical reinforcement of the materials have been proposed. Each graphene-based 3D material method of the two main developed families of approaches e.g. direct and non-direct approaches are discussed in detail in the following sections.

\subsection{Direct approaches to prepare 3D GBMs}

The CVD approach has been reported as a useful method for developing 3D graphene nanostructures that can enable the mass production of high-quality graphene materials within complex 3D architectures with controllable crystallinity and layer numbers, significantly enhancing the efficiency of graphenebased energy devices ${ }^{27,81}$. Generally, in CVD techniques, there are two routes often used in the production of 3D GBMs which are: (i) synthesis of $3 \mathrm{D}$ graphene composite materials and (ii) synthesis of $3 \mathrm{D}$ pure graphene after metal catalyst and oxide removal.

3D interconnected graphene within graphene-based composite materials. The first group who used CVD to synthesize 3D structures based on graphene was Chen's group 82. They particularly developed a method to form 3D-graphene foams with a $\mathrm{Ni}$ foam template. On the same principle as CVD used for $2 \mathrm{D}$ graphene growth, the procedure was based on decomposition of methane $\left(\mathrm{CH}_{4}\right)$ at $1000^{\circ} \mathrm{C}$ Then, the grown graphene film precipitated onto the porous surface of the nickel foam. The latter was then removed by etching. During this step, the graphene network could collapse; thus, a thin poly (methyl methacrylate) (PMMA) coating was deposited on the surface of the graphene sheets. A solution of heated acetone was then needed to remove PMMA and finally graphene foam/PDMS composites were formed by PDMS prepolymer infiltration into the free-standing graphene foams (Figure 7a). The morphology of the interconnected 3D graphene foam structure was confirmed by scanning electron microscopy (SEM) and TEM (Figure 7b-d). In addition, few years later, others kinds of template were used such as copper (Cu) ${ }^{83,84}$, cobalt (Co) ${ }^{85,86}$ and magnesium (Mg) ${ }^{87}$ to grow the 3D GBMs. Dong et al. reported a procedure using two facile steps to synthesize 3D GBMs involving cobalt oxide $\left(\mathrm{Co}_{3} \mathrm{O}_{4}\right)$ nanowires as catalyst. They found that the $3 \mathrm{D}$ graphene $/ \mathrm{Co}_{3} \mathrm{O}_{4}$ composite exhibited excellent electrochemical and electrocatalytic properties. Besides, the open pore system of the composite and large accessible active area made it a promising candidate for ion diffusion and transport kinetics ${ }^{88}$. In 2011, Ning et al. reported the formation of nanomesh 3D GBMs from $\mathrm{MgO}$ via CVD method. They claimed the unique porous structure and high surface area $\left(1654 \mathrm{~m}^{2} \mathrm{~g}^{-1}\right)$ having led to excellent electrochemical capacitance (up to $255 \mathrm{~F} \mathrm{~g}^{-1}$ ), cycle stability and rate performance ${ }^{87}$. Recently, apart from CVD, the combination of few routes for the production of 3D interconnected graphene within composite materials has been investigated more extensively. For example, Hu et al. have investigated the effect of rGO aerogels on $\mathrm{Ni}_{3} \mathrm{Fe} / \mathrm{Co}_{9} \mathrm{~S}_{8}$ composites by a calcinationhydrothermal approach for oxygen reversible electrocatalysis. They found that the SSA increased up to $137.5 \mathrm{~m}^{2} \mathrm{~g}^{-1}$ with a large pore-size range from 20 to $300 \mathrm{~nm}$ after adding rGO aerogels as support ${ }^{89}$. The introduction of GA to the composite provided the composite with more attached active sites, faster transportation of electrons/ions and improved structural stability 90,91. The synergistic effects of the conductive and 3D porous graphene network could potentially deliver high capacity and exhibit superior cycle life with good energy conservation. ${ }^{92}$. Typically, 3D GA or GBM has been used as a support for the composite materials in some applications like energy storage, as it is incredibly useful for the rapid transportation of electrolytes through their porous conductive structures, thereby facilitating extra charge-storage reactions. Wang et al. developed a novel graphene-based hybrid hydrogel by solvothermal reaction with Nickel (II) hydroxide and found that their modified composite 
material revealed large SSA up to $887 \mathrm{~m}^{2} \mathrm{~g}^{-1}$ and they demonstrated high specific capacities, speed capacities and longer cycle life in performance terms ${ }^{93}$. Wang et al. have observed modified 3D macroscopic $\mathrm{NiOOH}$ / GS hydrogels from another study, showing exceptional energy efficiency, high specific capacities and good rate capability. Using a similar approach, this composite material has a high SSA, $850 \mathrm{~m}^{2} \mathrm{~g}^{-1}$ and a well-defined $3 \mathrm{D}$ porous network of continuous pores varying from sub to few micrometers ${ }^{94}$. In the case of applications where a graphene based composite material is not suitable, other groups have met the challenge of preparing pure 3D GBMs. The reported routes to prepare these only carbon hierarchical structures are discussed in the following.

Pure graphene 3D GBMs prepared by CVD. Metalcatalyzed CVD routes for preparing 3D GBMs are now facile, scalable, and possibly compatible with industrial-scale production. The intrinsic drawbacks of these approaches include the relatively high amount of metal consumption, limited choice of metal microstructures and metal residues remaining in the products, which leads to an increase of the production price. However, for example, the use of an interfacial ultrathin metal film as catalyst that can be completely removed by etching at a final step is of great interest. Ma and co-workers reported such method using copper as catalyst at low temperature by a PECVD process enhancing that way the growth of vertical graphene (VG) ${ }^{95}$. They proposed, at the early stage of VG growth, a thin layer of amorphous carbon was formed on the substrate and later graphene nanosheets started to grow while the amorphous carbon remained. This condition led to simultaneous growth of graphene and carbon islands. Then, the graphene continued growing in vertical orientation due to sheath effect and ion bombardment between bulk plasma and the substrate. They also found that the growth of the VG was improved with as copper was used as catalyst. Zeng et al. reported that with few steps, they had successfully developed a novel 3D graphene fiber ${ }^{96}$. They started with the electrospinning of polyacrylonitrile (PAN) nanofibers with air stabilization and carbonization in $\mathrm{NH}_{3}$, and further with the growth of graphene sheets in a vertical orientation of the fibers (Figure 7).

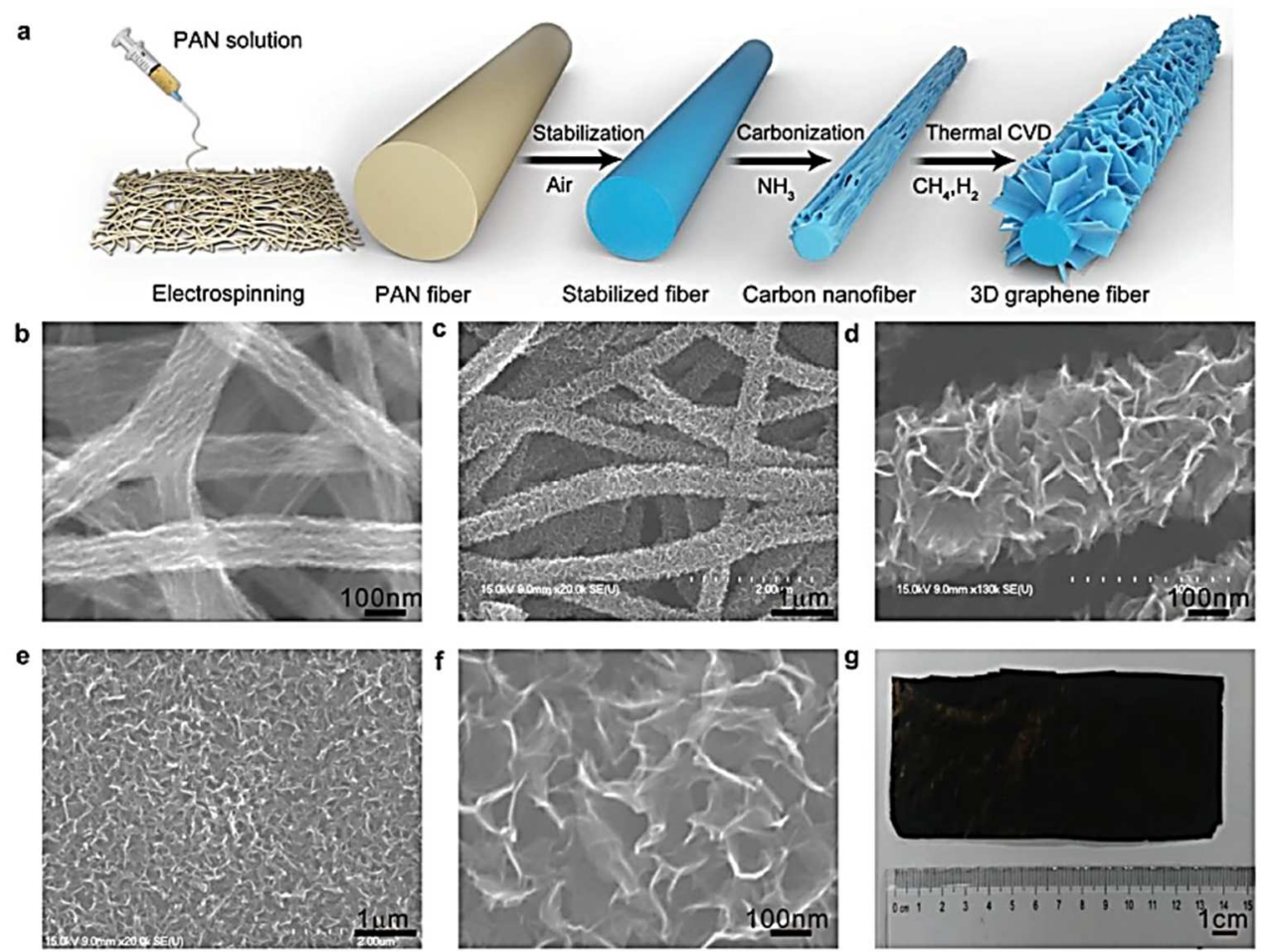

Figure 7 Preparation process and structure of the 3D graphene fibers. a) A schematic illustration of the preparation process. b) A SEM image of the carbon fibers carbonized in $\mathrm{NH}_{3}$. c,d) SEM images of the 3D graphene fibers grown for $4 \mathrm{~h}$ at $\mathrm{CH}_{4}$ concentration of $11.1 \%$ and $1100{ }^{\circ} \mathrm{C}$. e,f) SEM images of the $3 \mathrm{D}$ graphene fibers grown for $10 \mathrm{~h}$ at $\mathrm{CH}_{4}$ concentration of $11.1 \%$ and $1100{ }^{\circ} \mathrm{C}$. g) An optical image of the $3 \mathrm{D}$ graphene fibers membrane. Reproduced with permission from Ref. 96, Copyright Wiley-VCH 2018.

As a result, they found that the $3 \mathrm{D}$ graphene fibers were densely structured and connected with the edges completely exposed on the surface, resulting in superior performance in various property including electrical conductivity, electromagnetic shielding and hydrophobicity.

Discussion. Both of these two approaches may offer advantages and also drawbacks to the final materials. For example, 3D graphene hybrid materials can provide beneficial structures and advanced properties for some applications. In fact this strategy is also easy to create $3 D$ graphene with a combination of different types of nanomaterial onto or into the graphene surface ${ }^{97}$. However for some cases, the introduction of composite materials can result in significant energy-related performance degradation, since most of polymers and additives could not withstand high temperatures ${ }^{98}$. Besides, for 3D pure graphene synthesis, the graphene can normally be synthesized by metal-catalyzed growth. Essentially, this route promotes the production of high-quality graphene coatings on particular 3D architectures with controllable crystallinity and layers; they could 
thereby significantly enhance the graphene-based energy products.

\subsection{Self-assembly to prepare 3D GBMs}

Self-assembly of graphene into hierarchized macrostructures are usually synthesized from GO which is reduced by different methods, such as electrochemical reduction 99,100 , hydrothermal ${ }^{45}$, solvothermal reduction ${ }^{39}$ or chemical reduction ${ }^{101}$. As the starting based material, GO or rGO can be also used together with surfactants ${ }^{102}$ and polymers ${ }^{103}$ in order to limit agglomeration. Most of the researchers used this approach to fabricate self-assembled GBMs with more advanced and complex building blocks. For example, Lee and colleagues developed a complex 3D macroporous material which is mechanically flexible with tunable porous morphologies through chemically modified GO platelets. In addition, due to the polymerization process, the $3 \mathrm{D}$ complex structure may have formed, where the concentration of precursors and the chain length of grafted polymers played an important role ${ }^{104}$. Liu et al. also expected an advanced conjugated network of other materials such as CNTs, to link the graphene nanosheets ${ }^{81}$. In this section, we mainly categorized the self-assembly approaches into three ways which are process reduction, cross-linking and attachment of advanced functional groups including carbonyl, carboxyl, amino, silane, phosphate, and sulfhydryl.

Self-assembly of GO by electrochemical reduction. In electrochemical applications, the graphene-based materials were required to be deposited on the surface of an electrode combined with pre-synthesized polymers or conductive additives. In more recent years, a lot of researchers have come out with a more practical and facile method to directly deposit 3D graphenebased materials on the surface of an electrode. For example, copper electrodes were immersed into a $\mathrm{GO}$ aqueous dispersion (3.0 mg mL $\mathrm{mL}^{-1}$ ) and were amplified by a power amplifier with a signal frequency of $0.5 \mathrm{~Hz}$, duty ratio of $20 \%$ and peak to-peak voltage of $60 \mathrm{~V}$ using a pulse wave technique. After $2 \mathrm{~h}$, the product on the electrode was taken out and freeze-dried. A peculiar morphology of porous graphene dendrite (snowflake-like structure) was observed from the characterization test, where the graphene dendrite layers overlapped and converged, resulting in the formation of $3 \mathrm{D}$ graphene deposition. Such structure has revealed a high specific potential in an aqueous electrolyte (140 $\mathrm{F} \mathrm{g}^{-1}$ at $\left.5 \mathrm{~A} \mathrm{~g}^{-1}\right)^{81}$. Using the same approach, Chen and coworkers synthesized 3D graphene architectures (ERGO) with different secondary component such as conducting polymers, noble metal and metal oxide in GO aqueous dispersions. From their results, ERGO-polyaniline composite showed high specific capacitance of $716 \mathrm{~F} \mathrm{~g}^{-1}$ at charge current density of $0.47 \mathrm{~A} \mathrm{~g} \mathrm{~g}^{-1} 105$. Basically, these secondary components were chosen based on their high surface area and conductivity, low mass transport resistance and easy electrode modification with fast and tunable electrochemical synthesis ${ }^{106,107}$. Such 3D structured graphenebased material was designed as thin films covering the electrode surface and they were especially used for applications such as electronic ${ }^{108}$, sensing ${ }^{109}$, solar cells ${ }^{110}$, supercapacitors ${ }^{111,112}$, batteries ${ }^{113}$, electrochemical energy storage 14 etc. The approaches described below allow to prepare higher quantities of materials in the form of monolith of often several $\mathrm{cm}^{3}$ useful for other application field mainly environmental.

Self-assembly of GO by hydrothermal or solvothermal reduction. Hydrothermal or solvothermal reduction are effective to synthesize 3D graphene-based hybrid materials. The hydrothermal method can be defined as a technique that induces chemical reactions in aqueous solution above the boiling point of water. The solvothermal method usually involves organic solvents (instead of water) and the chemical reaction occurs at a temperature higher than the solvent boiling point under high pressure. Essentially, in both processes, first, GO is homogeneously dispersed in the chosen solvent and the GO's oxygenated functional groups are reduced during the chemical reaction leading to attractive hydrophobic interactions occurring between the produced rGO nanosheets. Depending on the used experimental conditions, the strength of the integrated stacking system increases as well as the number of cross-links often under addition of heat and energy. These approaches can be applied to some other materials to have the 3D heterostructures as the combination of other components may alter the structures as well as the functions to support certain forms of application. In the case of GBMs prepared using the hydrothermal method, it is known that the $\mathrm{pH}$ plays an important role on 3D graphene properties as also discussed later. Thus, Garcia-Bordejé et al. conducted an experiment on the effect of $\mathrm{pH}$ and time towards the microstructure and surface chemistry of Gas ${ }^{114}$. Figure 8 shows the mechanism of the hydrothermal reduction process at the various $\mathrm{pH}$ values. From the results, they found that, in alkaline conditions, the morphology of the 3D macrostructures was twisted and potentially bent at the border resulting in more open structures with higher porosity while in the acidic medium, the aerogel architecture was less porous and denser. 

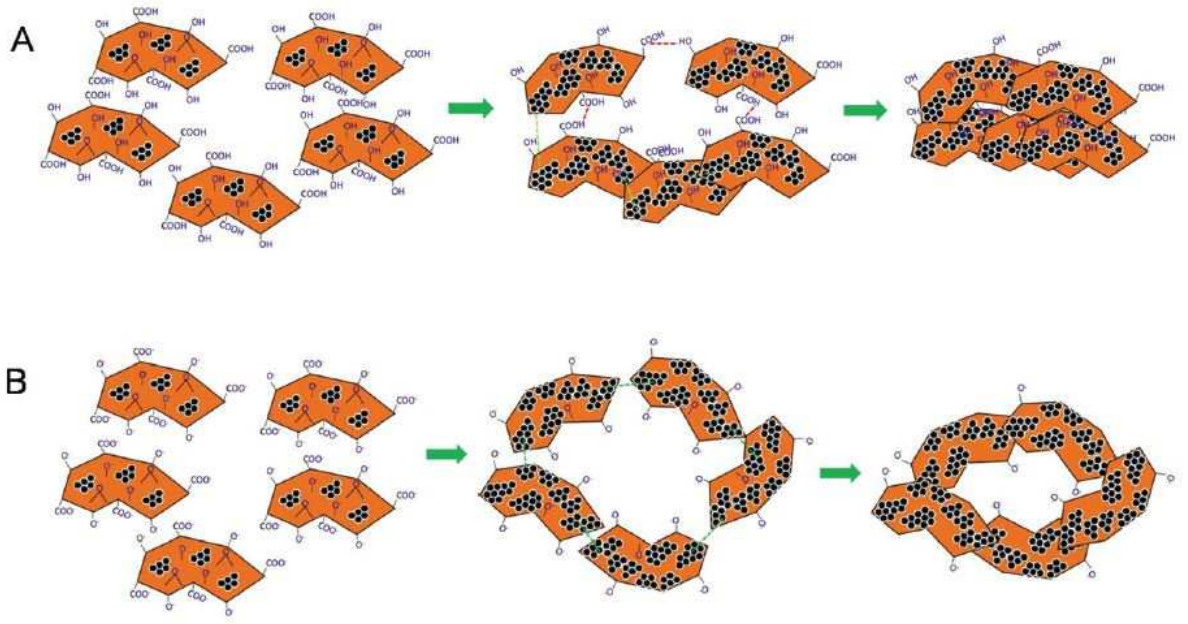

Figure 8 Scheme of the possible mechanisms of the hydrothermal reduction process under $\mathrm{pH} 3(\mathrm{~A})$ and under $\mathrm{pH} 11(\mathrm{~B})$ at different stages. The red dashed lines indicate $\mathrm{H}$-bond interactions while the green dashed lines indicate van der Waals hydrophobic interactions. Reproduced with permission from Ref. ${ }^{114}$, Copyright The Royal Society of Chemistry 2015.

The hydrothermal reduction process mechanism was commonly started with GO synthesizing using the modified Hummers' method and continued with dispersion in water eventually with addition of surfactant as it could easily disperse graphene due to its strong hydrophilicity and electrostatic repulsion impact ${ }^{115}$. Generally, the oxygenated functionalities decreased significantly after the hydrothermal or solvothermal reduction process, and a large amount of $\pi$-conjugation was restored to make it easy to turn to rGO. In this condition, interfaces via all the bonds were capable to organize complex architectures such as 3D building blocks ${ }^{116}$. For example, hybrid $\mathrm{ZnO} / 3 \mathrm{D}$ graphene-based structures could be developed ${ }^{117}$. Zinc (II) cation and ammonia were mixed in solution by a hydrothermal process to form a complex compound $\left[\mathrm{Zn}\left(\mathrm{NH}_{3}\right)_{4}\right]^{2+}$. Under alkaline conditions, the formed cations were associated with $\mathrm{GO}$ resulting in $(\mathrm{GOZn})^{\mathrm{z}+} \mathrm{ZOH}^{-}$neutral compound. After reaction with $\mathrm{Zn}(\mathrm{OH})_{4}{ }^{2-}$, $\mathrm{ZnO}$ solid compound could appear both as $\mathrm{G}(\mathrm{ZnO})$ retained particles on graphene structure and as $\mathrm{ZnO}$ free particles.

Interestingly, doping of graphene within the GBMs could be efficiently prepared using simple one-step hydrothermal or solvothermal route. Yang et al. have proposed a facile hydrothermal method to produce nitrogen-doped graphene aerogels (N-GA). Initially, GO was reduced by a hydrothermal treatment in the presence of ammonium hydroxide in Teflon-lined reactor which was sealed in a steel autoclave. After freeze-drying, the N-GA possessed hierarchical porous structure with SSA around $200 \mathrm{~m}^{2} \mathrm{~g}^{-1}$. According to the XRD study, N-GA exhibits a large diffraction peak, revealing the typical rate of GA. This was also supported by the SEM analysis, showing 3D porous structure interconnected. The N-GA enabled efficient diffusion of both bacterial cells and electron mediators in the interior space of a 3D electrode ${ }^{118}$.

Long et al. reported a large scale chemical reduction and nitrogen doping of GO they achieved simultaneously using
$\mathrm{N}_{2} \mathrm{H}_{4}$ and ammonia under hydrothermal environment ${ }^{119}$. They found that the structure and surface chemistry of the modified graphene sheets were strongly dependent on the hydrothermal temperature as different temperatures could play a dominate role in the nitrogen doping and multiple reactions may occur simultaneously. With a similar approach, Sui et al. successfully synthesized N-GA with some attractive characteristics such as high nitrogen content, high SSA, outstanding electrical conductivity with good rate performance, and long-term cycling stability for supercapacitor electrodes and gas adsorbents ${ }^{120}$. In this process, GO and ammonia were adopted as carbon and nitrogen source, respectively. They used a Teflon-lined stainlesssteel autoclave, at $180^{\circ} \mathrm{C}$ for $12 \mathrm{~h}$. The as-prepared hydrogel was dialyzed for three days and converted into aerogel by freezedrying. Figures 9a-9c show the morphology and structure of asprepared N-GA by SEM and TEM. From the results, the N-GA exhibited a structured and entangled porous network with randomly oriented graphene sheets. The observed hierarchical porous structure facilitated rapid ion transfer pathways during the process of charge-discharge. Figures 9d-9f also reveal other findings from thermal gravimetric analysis (TGA), Fouriertransform infrared spectroscopy (FTIR), and Raman spectroscopy investigation, respectively. The produced N-GA possessed large SSA which is up to $830 \mathrm{~m}^{2} \mathrm{~g}^{-1}$, Besides, the good electrical conductivity and wettability were responsible to help the electron transport and electrolyte permeation, further improving its electrochemical performance. Moreover, these N-GAs were shown to be a good adsorbent with a high carbon dioxide uptake of $11.3 \mathrm{wt} \%$ at 1.0 bar and $273 \mathrm{~K}$, thanks to the large SSA and high nitrogen content. Due to all the excellence performance, the as-prepared N-GAs could hold promise in the fields of energy and environment. 

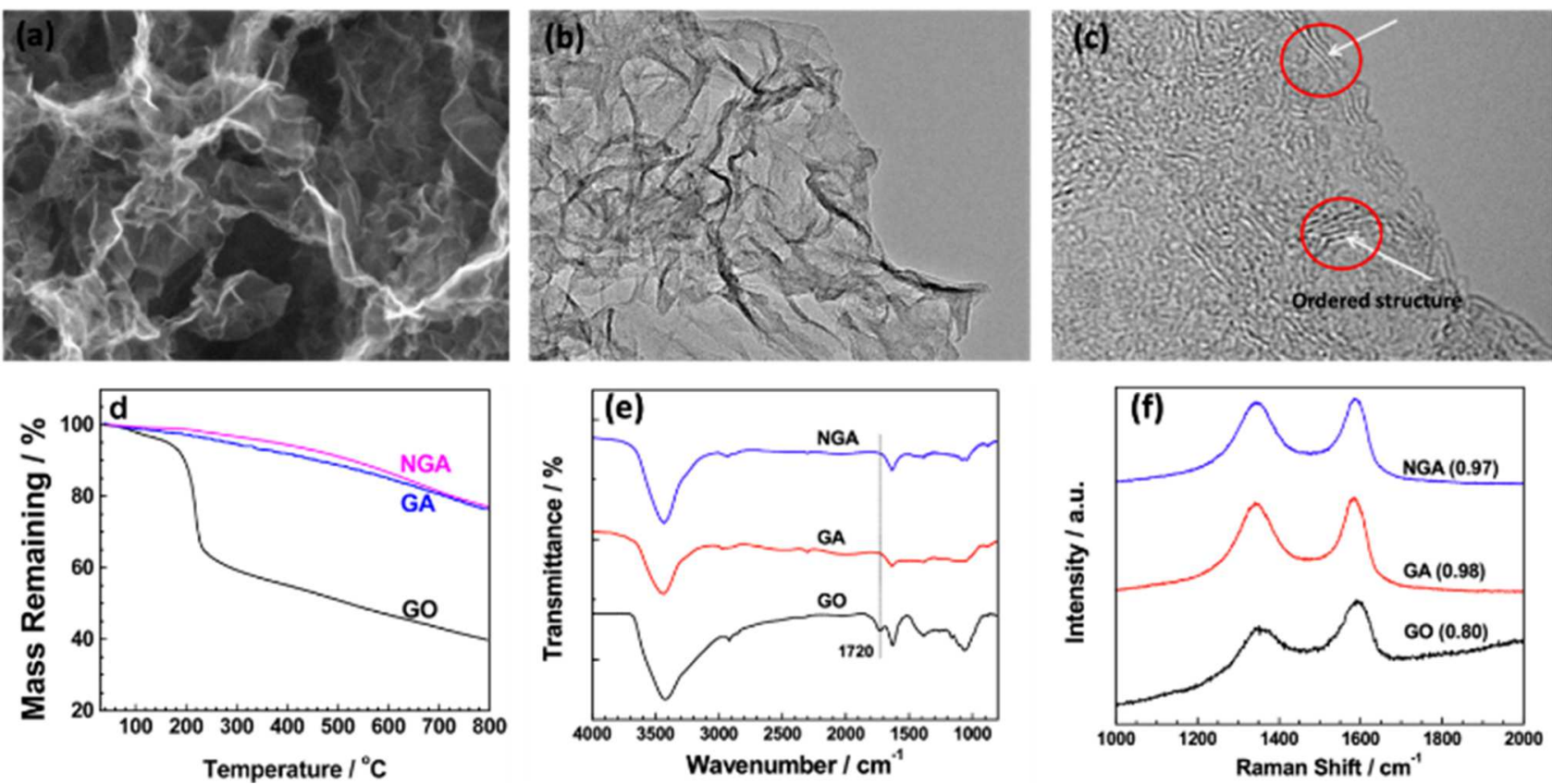

Figure 9 Images and characterization of the N-GAs prepared by Sui et al. N-GA imaging by (a) SEM, (b) TEM image at low magnification, (c) TEM at high magnification, (d) thermal gravimetric analysis curves, (e) FTIR spectra of GO, GA and (f) Raman spectra of GO, GA, and N-GA. Reproduced with permission from Ref. ${ }^{120}$, Copyright American Chemical Society 2015.

Quan et al. have presented a novel approach to synthesize sulfurdoped graphene aerogels (S-GAs) via a solvothermal method using dimethyl sulfoxide (DMSO) as the S-containing organic molecule. A mixture of $\mathrm{NaOH}$ and DMSO was added into a threeneck flask with a reflux condenser and heated under a $\mathrm{N}_{2}$ gas flow for $1 \mathrm{~h}$. Similarly, to the preparation of $\mathrm{N}$-doped graphene, dimethylformamide (DMF) and sodium were sealed into a Teflonlined stainless-steel autoclave and heated at $180^{\circ} \mathrm{C}$ for $12 \mathrm{~h}$. The synthesized heteroatom-doped graphene showed a large SSA with additional active edge sites, enhancing the performance of energy storage and conversion applications ${ }^{15}$. Moreover, according to X-ray photoelectron spectroscopy (XPS) and elemental analysis results the authors conducted, the $\mathrm{S}$ or $\mathrm{N}$ atoms were covalently bonded to the network of graphene with a sulfur and nitrogen content as high as 22.83 and 12.25 wt.\%, respectively ${ }^{121}$

Freeze-drying. Freeze drying or freeze casting is one of the step used in developing 3D GBMs as it eliminates the solvent without damaging the 3D graphene framework by utilizing the anisotropic solidification behavior of the used solvent, e.g. water or organic solvents ${ }^{122}$. Besides, as mentioned earlier, freezedrying is normally used in conjunction with hydrothermal or solvothermal reduction process. After the gelation by reduction of $\mathrm{GO}$ in a dispersion state, the solvent is gently removed by freeze drying to preserve the hierarchical porous structure of the material. Zhang et al. studied the correlation between two different approaches to synthesize 3D porous graphene sponges ${ }^{123}$. The first method was through soap bubble foams used as templates and the second method involved direct freeze-drying of $\mathrm{GO} /$ surfactant solutions. From the study, they found that by tuning the freezing media, stirring and freezing rate or adding additives, the structure of the pores significant changed. Besides, the addition of surfactant could provide better GO sheet dispersion, resulting in a high SSA which increased from 52 to $105 \mathrm{~m}^{2} \mathrm{~g}^{-1}$.
Rodríguez-Mata et al. conducted a study to evaluate and compare the degree of reduction or gelation effects on the formation of microchannels ${ }^{124}$. In this study, GO was first reduced to rGO by hydrothermal reduction, and later the hydrogel obtained was frozen using two separate methods, bulk freezing $(B F)$ and unidirectional freezing (UF). They found that UF offered substantially lower densities and higher specific pore volumes than BF for the two shortest periods ( 45 and $75 \mathrm{~min}$ ), and that UL also resulted in more ideal cylinders than BF. In addition, in terms of efficiency, the UF approach of aerogels contributed to the creation of GA with aligned and continuous microchannels, allowing an intermediate cross-linking degree of rGO nanosheets, thus providing a higher absorption ability of non-polar solvent and aromatic compounds.

Self-assembly of GO by chemical reduction. Chemical reduction is one of the most frequently used approaches to prepare 3D GBMs. Usually in this method, either organic or inorganic reducing agent is simply added to GO dispersed in water to induce its reduction and it gives rise to $\mathrm{rGO}$ material. Advantageously, such chemical reaction occurs at low temperatures (below $100{ }^{\circ} \mathrm{C}$ and often at room temperature) compared to hydrothermal and solvent thermal methods ${ }^{125}$. In this method, several common reducing agents are used: hydrazine ${ }^{126}$, vitamin C ${ }^{127}$, sodium ascorbate ${ }^{128}$, sodium borohydride $\left(\mathrm{NaBH}_{4}\right)^{129}$ etc. (cf. also section 2.2.3). Banda et al. used hydrazine (HD), ethylenediamine (ED) and 1,4diaminobutane (DB) as reductant to conduct a direct synthesis of highly reduced graphene hydrogels ${ }^{126}$. The GO was mixed with diamine and heated in an oil bath at $80^{\circ} \mathrm{C}$ for $24 \mathrm{~h}$ without stirring. The BET result indicated that graphene hydrogel with $\mathrm{HD}$ has the maximum SSA of $1433 \mathrm{~m}^{2} \mathrm{~g}^{-1}$, followed by ED $\left(677 \mathrm{~m}^{2} \mathrm{~g}^{-1}\right)$ and DB $\left(335 \mathrm{~m}^{2} \mathrm{~g}^{-1}\right)$, respectively. Likewise, they found that the graphene hydrogel with HD displayed a high electrical conductivity which could be suitable for applications with high 
supercapacitor levels. Similarly, Yang et al. conducted a study to chemically reduce $\mathrm{GO}$ using $\mathrm{NaBH}_{4}-\mathrm{CaCl}_{2}$ system at room temperature ${ }^{130}$. In this study, $\mathrm{CaCl}_{2}$ served as a catalyst to improve the $\mathrm{NaBH}_{4}$ reduction capability and promote the removal of hydroxyl groups as well as the preservation of electronic graphene conjugation. Besides, rGO prepared with $\mathrm{NaBH}_{4}-\mathrm{CaCl}_{2}$ system had a higher $\mathrm{C} / \mathrm{O}$ atomic ratio from the XPS study, which lead to less resistivity and less oxygenated functional groups than rGO prepared without $\mathrm{CaCl}_{2}$.

Zhang and his colleagues successfully developed 3D graphene assembly by using a low-cost and environmentally friendly reduction medium ${ }^{131}$.In their method, a mixture of oxalic acid (OA) and sodium iodide (Nal) was mixed with $\mathrm{GO}$ and then sonicated and moved to an oil bath at $90{ }^{\circ} \mathrm{C}$ for $12 \mathrm{~h}$ without stirring. Using this approach, they found that the surface area of the GA is $151 \mathrm{~m}^{2} \mathrm{~g}^{-1}$ and the reduction of the GO by OA and Nal preserved the strongly conjugated graphene structure that infused the resulting GAs with electrically conductive properties. In the work from Chen and Yan, four separate reducing agents were used, including sodium bisulfite $\left(\mathrm{NaHSO}_{3}\right)$, sodium sulfide $\left(\mathrm{Na}_{2} \mathrm{~S}\right)$, vitamin $\mathrm{C}$, hydrogen iodide $(\mathrm{HI})$, and hydroquinone under a temperature of $95{ }^{\circ} \mathrm{C}$, which was ideal for preserving highly ordered macropores in the prepared 3D graphene architectures ${ }^{132}$ The GBMs by using $\mathrm{HI}$ have shown to lead to the highest value for electrical conductivity and as well a high value in density and degree of reduction. The authors believed the density and degree of reduction could be the important factors for electrical conductivity as well. The self-assembly could evolve, triggered by the hydrophobic and $\pi-\pi$ stacking interactions of the GO structures, resulting in high mechanical strength, thermal stability and electrical conductivity of 3D graphene framework ${ }^{133}$. Similarly, Zhang et al. proposed a one-step chemical reduction of GO assemblies in the oil-water system using $\mathrm{NaHSO}_{3}$ as a reducing agent and co-emulsifier for the GO-stabilized emulsion ${ }^{134}$. Figure 10 illustrates the synthesis process of GA, complementary with the SEM images. In this process, they used a Teflon-lined stainless-steel autoclave, at $70^{\circ} \mathrm{C}$ for $12 \mathrm{~h}$ to allow the reduction of $\mathrm{GO}$. As GO was gradually reduced, the concentration of oxygen decreased due to the removal of functional groups, inducing $\mathrm{rGO}$ to stack tightly all over the oil droplets. This condition allowed the development of a hexagonal network dominated by hydrophobic and $\pi-\pi$ interactions of conjugated $r G O$. The GA images from the SEM results reveal a highly arranged honeycomb-like structure containing interconnected macropores, with the size of tens micrometers. In terms of properties, the GA exhibited ultra-low weight and high mechanical strength which could be acceptable for use in diverse fields.

An alternative method for building a 3D graphene-only sponge (CGS) using ammonium sulfide $\left(\left(\mathrm{NH}_{4}\right)_{2} \mathrm{~S}\right)$ and ammonia $\left(\mathrm{NH}_{3}\right)$ solutions under mild conditions was reported. Throughout the process of reduction, the hydrophobic and $\pi-\pi$ conjugated structures of rGO were created. These CGS have shown a significant interconnection between the building blocks inducing great stability and mechanical strength with high compressibility properties ${ }^{135}$. Spilarewicz-Stanek and coworkers have prepared 3D graphene hydrogels for dye adsorption and catalysis application using L-cysteine (L-Cys) under mild condition by simultaneous self-assembly and reduction of graphene oxide (GO) ${ }^{136}$. L-Cys is classified as environmentally friendly substances with diverse functional groups including $-\mathrm{NH}_{2},-\mathrm{SH}$ and -COO-. They stated that L-Cys molecules were interacting with each other to create a polymeric network configuration in solution that could act as a template for the 3D framework GO self-assembly mechanism. Then, at a temperature of $90{ }^{\circ} \mathrm{C}$, the L-Cys were gasified $\left(\mathrm{NH}_{3}\right.$ and $\left.\mathrm{H}_{2} \mathrm{~S}\right)$ and the emitted $\mathrm{H}_{2} \mathrm{~S}$ reduced $\mathrm{GO}$, allowing the graphene-based $3 \mathrm{D}$ material to be prepared in one step. This latter not only demonstrated high mechanical strength and thermal stability, yet also displayed great adsorption capacity against organic dyes ${ }^{137}$.

Figure 10 Synthesis process of GA from the assembly of GO at oil-water interface and the subsequent chemical reduction, complementary with the SEM images. (a) $\mathrm{GO}$ concentration of $2 \mathrm{mg} \mathrm{mL}^{-1}$, (b) emulsion of $\mathrm{GO}, \mathrm{NaHSO}_{3}$ and cyclohexane, (c) graphene hydrogel with hexagonal pore connecting the boundary with six other identical pores, providing a strong linking bridge, (d) view of the GA. Reproduced with permission from Ref. ${ }^{134}$, Copyright Nature Publishing Group 2016

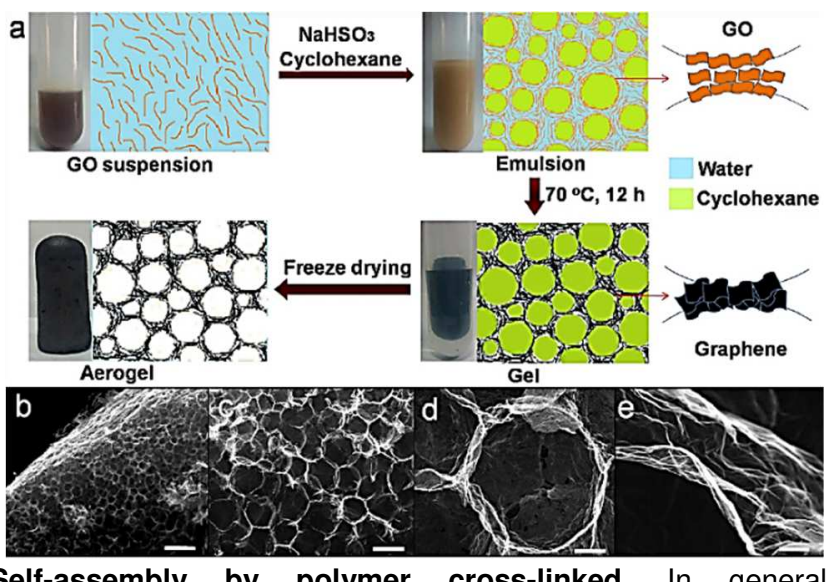

Self-assembly by polymer cross-linked. In general, development of 3D GBMs by assistance of polymers has been shown to be beneficial in improving the physical properties of the materials. Polymers can interact with graphene thanks to either $\Pi-\pi$ or hydrogen interactions. In 2016, Fang et al. synthesized a highly ordered 3D GBMs with the aid of poly (vinyl alcohol) (PVA) polymers for molecular transfer ${ }^{138}$. Their preparation method comprised three steps which are pre-reduction of $\mathrm{GO}$ by $\mathrm{NaBH}_{4}$, sulfonation using sulfanilic acid $\left(\mathrm{C}_{6} \mathrm{H}_{7} \mathrm{NO}_{3} \mathrm{~S}\right)$ and sodium nitrite $\left(\mathrm{NaNO}_{2}\right)$ and lastly the post-reduction by hydrazinium hydroxide $\left(\mathrm{N}_{2} \mathrm{H}_{5} \mathrm{OH}\right)$. During the sulfonation process, a simple acid base reaction took place where after the addition of hydrochloric acid, nitroso ions were formed by the reaction of sodium nitrite in the acidic medium to form diazonium salt ${ }^{139}$. The sulphonic acid groups were successfully grafted to the surface of rGO as it could be evidently seen in the FTIR spectrum. Later, the preparation of modified graphene/PVA was performed by hydrothermal reaction at $180^{\circ} \mathrm{C}$ for $6 \mathrm{~h}$. During this process, the PVA chains acted as bridges to link two adjacent sheets of the modified graphene and finally formed a $3 \mathrm{D}$ bulk composite with uniform spacing of the interlayer ${ }^{138}$.

Utilization of conductive polymers was also investigated to combine electron conductivity and high-surface area to improve electron transfer in electrode materials. Moussa and co-workers reported how outstanding 3D graphene based hydrogels were synthesized in a GO aqueous solution through cross-linking by polyaniline (PANi), polypyrrole (PPy), and poly(3,4-ethylenedioxythiophene) (PEDOT) ${ }^{140}$. The intermolecular forces generated between the conducting polymer chains and their system allowed the hydrogel structure to be retained and behaved as self-cross linkers. The polyaniline nanofiber hydrogel consequently exhibited high value of gravimetric capacitance up to $492 \mathrm{~F} \mathrm{~g}^{-1}$ which could be used for supercapacitors.

In another study, Wang et al. synthesized 3D self-assembly polyethyleneimine-modified graphene oxide hydrogel (PEI-GHs) and they investigated the adsorption performance of uranium 
using these hybrid materials ${ }^{141}$. In this study, PEI was chosen because it could be easily grafted to the matrix since it has both secondary amines in the linear chain and primary secondary and tertiary amino groups in the branched amines ${ }^{142}$. A possible mechanism involving PEI being either directly adsorbed on the GO surface or covalently functionalized by amide cross-linking reaction between $-\mathrm{COOH}$ groups of $\mathrm{GO}$ and $-\mathrm{NH}_{2}$ groups of $\mathrm{PEI}$. Then, after the freeze-drying, the assembled structure retained its structural quality, resulting in the 3D porous hierarchical structure. Most important, the PEI-GHs displayed large adsorption capacity and great removal efficiency in high concentration uranium (VI) when compared to graphene hydrogel due to the formation of strong amide bonds.

Self-assembly by organic linker. Organic selfassembly provides an easy way to synthesize functional nanomaterials with the aid of some organic linker like glucose, bcyclodextrin, chitosan, and DNA molecules. These latter can be linked to graphene or GO into a 3D network by covalent bonds. $\mathrm{Xu}$ et al. reported a strategy way to form 3D multifunctional GO/DNA composite self-assembled hydrogel (GO/DNA SH) ${ }^{143}$. Double-stranded DNA (dsDNA) was added to an aqueous solution of GO under heating condition at $90{ }^{\circ} \mathrm{C}$ for $5 \mathrm{~min}$. They found that the dsDNA was unwound during the heating process to single-stranded DNA (ssDNA) chains that bridged adjacent GO sheets via strong noncovalent interactions. Besides, their GO/DNA SH showed a good stability, possibly due to the strong binding of DNA chains by several noncovalent interactions, including $\pi-\pi$ stacking and hydrophobic interactions between DNA bases and GO structure, as well as electrostatic and hydrogen bonding interactions. Additionally, there were parameters that needed to be addressed during the creation of 3D GO/DNA SH. For example, the concentration of GO and dsDNA, as with an ideal condition, it could increase the mechanical strength of the resulting self-assembled hydrogel. Indeed, the authors believed that the reliability of the 3D network was critical in designing and manufacturing a hierarchical graphene-based material, and this could be achieved by increasing the cross-linking sites between GO sheets and DNA chains.

Guo and coworkers presented the modification of chitosan/GO composite as an effective adsorbent for dye removal ${ }^{144}$. They evidenced that the $\mathrm{NH}_{2}$ groups belonging to the chitosan chains have reacted with the $\mathrm{COOH}$ groups on $\mathrm{GO}$ as the $\mathrm{C}-\mathrm{O}$ stretching vibration (by FTIR) of $\mathrm{NHCO}$ and the $\mathrm{N}-\mathrm{H}$ bending of $\mathrm{NH}_{2}$ were shifted to a lower value and the intensity of acetylated amino group NHCO was increased. In this case, a various kind of noncovalent interactions were involved leading to the observed strong binding of chitosan to GO or rGO surface. Additionally, they found that the structure of chitosan was slightly altered by adding some amount of GO or rGO. This could be due to interactions involving electrostatic and hydrogen bonding between the prime amine base and the oxygen-containing GO groups. The modified chitosan / GO composite was then tested as an adsorbent in textile wastewater for removal of reactive dyes and showed a significant result with a maximum adsorption capacity of $32.16 \mathrm{mg}$ $\mathrm{g}^{-1}$.

Self-assembly by chemical grafting. We have seen that self-assembly by process reduction and cross-linking are promising methods to integrate various nanostructured materials into macroscopic substances. Another route that can be used to initiate the 3D GBMs by attaching functional groups such as carbonyl, carboxyl, amino, silane, phosphate, and sulfhydryl on the surface or edges of the graphene. In that case, other than GO which bears a lot of structural defects, high structural quality graphene materials, e.g. GNPs or graphene flakes, can be also used. The main advantage for using good quality graphene is the optimization of physical properties such as thermal and electrical properties that can be desired for applications in energy or catalysis. Besides, since the graphene nanosheets are covalently linked, they could exhibit higher mechanical properties than for 3D GBMs where only $\mathrm{H}$-bonding, $\pi-\pi$ or van der Waals interactions are responsible for the mechanical strength. However, for such less common approaches to prepare 3D GBMs, many challenges and unresolved issues remain. Zhang et al. have studied the effect of silane and surfactant treatments on GNPs for the mechanical and thermal properties of silicone rubber (SR) composites 145. Two chemical compounds that are aminopropyltriethoxysilane (APTES) and vinyltrimethoxysilane (VTMS) were used in water/ethanol mixtures for the covalent modification of GNPs by silane. Based on their results, VTMS$\mathrm{GnP} / \mathrm{SR}$ tensile strength has been improved and this could be due to chemical interactions with the silicone chains $\left(\mathrm{Si}-\mathrm{CH}_{2}=\mathrm{CH}_{2}\right)$, resulting in a strong interfacial contact between the GNPs and matrix. In addition, after surfactant (Triton X-100) addition, the highest thermal conductivity with an increment of $57.3 \%$ and good mechanical performance were observed. They believed that this could be attributable from the hydrophobic octyl group of the surfactant that was absorbed on the surface of the GNPs, while the hydrophilic part was associated with silicone by hydrogen bonding.

Similarly, Yadav and co-authors performed the modification of GNPs by covalent functionalization process by adding various functional groups such as carbonyl group, carboxyl group and hydroxyl group to the GNPs surface to improve the mechanical and thermal properties of polyurethane nanocomposites ${ }^{146}$. The reaction was conducted accordingly to principle of diazotization reaction where the used chemical process converted a primary aromatic amine into the corresponding amine diazonium salt ${ }^{147}$. The procedure started by mixing GNPs with 4-aminophenethyl alcohol and then 3-methyl butyl nitrite was gradually injected in a stirring state at a temperature of $80^{\circ} \mathrm{C}$ for $12 \mathrm{~h}$. Finally, GNPs/Pu nanocomposites were prepared by a polymerization method. During the functionalization process, the surface of GNPs was first occupied with the primary alcohol groups to form GNP-OH. This process could possibly happen due to surface epoxy aminolysis with 4-aminophenethyl alcohol along with the existence of 3-methyl butyl nitrite and the reaction of surface carboxylic acid groups to form diazonium salt with the amino alcohol. In addition, the polyurethane nanocomposites (PU) with the functionalized GNPs showed a high Young's modulus which is 1.3 times higher compares to pristine PU and GNPs/PU. The use of carboxylic acid functions present in GNPs can create the linkage with other chemical molecules which could be used as starting materials for advanced covalent functionalization to develop more complex graphene structures ${ }^{146}$.

Alzate-Carvajal and coworkers functionalized GO with aromaticaliphatic amines such as 1-aminopyrene (AP), 1,5diaminonaphthalene (DAN) and 1-octadecylamine (ODA), 1,12diaminododecane (DAD), respectively by condensation and necleophilic addition reactions between $-\mathrm{NH}_{2}$ groups of the amino 
acids and carboxylic acid or epoxy groups on the GO ${ }^{148}$. The APand DAN-functionalized GO exhibited a scrolled structure attributed to $\pi-\pi$ stacking interactions between the aromatic ring of AP and DAN and GO, as well as $\mathrm{H}$-bonds between the amino groups and O-containing groups of GO layers, while ODA and DAD were covalently intercalated with structured interlayer spacing between GOs. In addition, in the case of GO-ODA, the highest levels of amine species were found, followed by GO-DAD, GO-AP and GO-DAN and the improvement in mechanical and thermal stability, as well as electrical conductivity, was shown for all functional samples.

In 2015, Samadaei et al. synthesized functionalized GO with ethylenediamine (EDA) and poly (amidoamine) (PAMAM) simultaneously with the reduction process to form the 3D GBMs 149. EDA was used to reduce the GO and to convert epoxides into amino alcohol. After N, N'-dicyclohexylcarbodiimide and 4dimethylami-nopyridine were introduced, the occurred crosslinking with $\mathrm{rGO}$ resulted in the final product of $\mathrm{rGO}-\mathrm{NH}_{2}$, which could be used in further modification processes such as amination. Other than reducing and functionalizing GO, EDA also played a role to link the GO nanosheets within the hierarchical structure. The proposed mechanism is shown in figure 11. The bonds could occur based on the two amine $\left(-\mathrm{NH}_{2}\right)$ functionalities on both sides of the ethylene moiety that could attack the epoxy carbon / carboxylic moiety of two GO layers, helping to link the structure and developing that way a 3D porous graphene network. Figure 12 below summarizes the possible approaches designed so far for the synthesis of 3D GBMs. Both direct and self-assembly (ondirect) approaches are given with the used method and the precursors required for each of them.

\section{Discussion}

Surface and porosity of 3D GBMs. Formation of 3D GBMs is especially desired to exploit their surface area to develop innovative materials for their application in energy and environment. High SSA and highly interlinked pores make these 3D GBMs the ideal material for the next generation of nanostructured materials. The surface area of 3D GBMs is the main characteristic usually reported in literature because it strongly impacts their performances. The porosity (pore size distribution (PSD) or pore volume) of GBMs is the second key parameter studied. Generally, the GBM pore size can be categorized into three main scales, (1) in-plane pores for carbon porous materials ${ }^{150}$; (2) interlayered pores for $2 \mathrm{D}$ graphene ${ }^{151}$; (3) in-plane pores and interlayered pores for 3D graphene ${ }^{152}$.
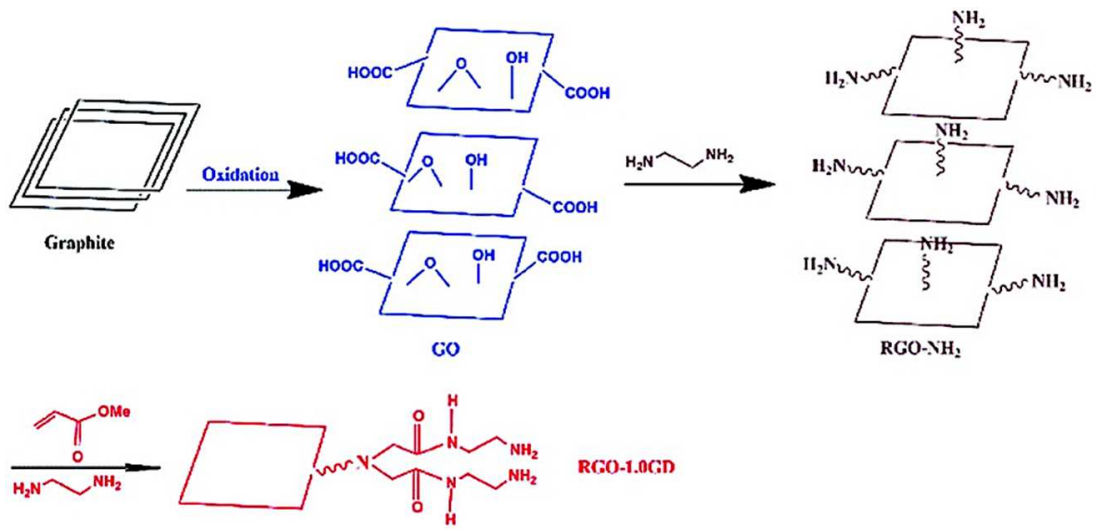

Figure 11 Possible mechanism of PAMAM grafting onto GO nanosheets to form 3D porous graphene network. Reproduced with permission from Ref. ${ }^{149}$, Copyright The Royal Society of Chemistry 2016. 


\section{Direct Synthesis Approach \\ - Template-assisted Chemical Vapor Deposition (CVD) \\ - 3D Graphene composite nanostructure \\ - 3D Graphene nanostructure}

Self-assembly Approaches
- Self-assembly by reduction of
GO
- Electrochemical reduction
- Hydrothermal / solvothermal
reduction
- Chemical reduction
- Self-assembly by cross-linking
- Polymer cross-linked
- Organic linker
- Chemical function grafting
- Carbonyl, carboxyl, amino,
silane, phosphate, and
sulfhydryl

Figure 12 List of the methods with their corresponding material precursors used to construct 3D GBMs.

In addition, if the pore size is too small, the guest molecules or reactant compounds, diffusion within the material and access to the reactive surface is limited. Moreover, too large pore diameter or two weak interconnectivities within the GBM will lead to fragile materials which consequently lose their interest for any application. Table 1 reviews the progress of the works regarding the surface area, the porosity and density (if available).

As mentioned earlier, the theoretical (and maximum) value of one monolayer graphene (both sides) is as high as $2630 \mathrm{~m}^{2} \mathrm{~g}^{-1}$; the researchers aim at maximizing the surface of their 3D GBMs in order to reach the maximum of accessible surface knowing that the highest possible surface for the prepared 3D GBMs usually considered is half of the theoretical value of SLG ${ }^{153}$, e.g. $\sim 1300$ $\mathrm{m}^{2} \mathrm{~g}^{-1}$. The main reason is that most often, FLG (including GO and rGO) or MLG are used as graphenic material to build the macroscopic structure. This is difficult to give the value in surface these GBMs could reach, however, several hundreds of $\mathrm{m}^{2} \mathrm{~g}^{-1}$ could be a minimum for a reasonable surface expected for these GBMs considering the high surface of the building block used. Even if most of the works report surface area below $1000 \mathrm{~m}^{2} \mathrm{~g}^{-1}$, GBMs with exceptional high surface areas $\left(>1000 \mathrm{~m}^{2} \mathrm{~g}^{-1}\right)$ have been reported (Table 1). These 3D GBMs could be prepared by either the direct method 154,155 or by the self-assembly approach 126,156-158. Except for these works, yet there is still limitation and most of the reported works seems to have moderate (500-1000 $\left.\mathrm{m}^{2} \mathrm{~g}^{-1}\right)$ and low surface $\left(50-500 \mathrm{~m}^{2} \mathrm{~g}^{-1}\right)$. In some cases, the obtained 3D GBMs displayed a hierarchical porous network structure containing mesopores with low surface of less than 100 $\mathrm{m}^{2} \mathrm{~g}^{-1}$ (Table 1). Within the macrostructure, the 2D graphene nanosheets suffer from aggregation during the growth or the selfassembly process due to attractive forces, such as $\pi-\pi$ or van der Waals. Many 2D graphene nanosheets systems can be used for 3D GBM designing and the relevant parameters impacting the self-assembly mechanisms are difficult to be tested and evaluated separately. In recent works, some of them such as $\mathrm{pH}^{114}$ or $2 \mathrm{D}$ graphene size ${ }^{159}$ have been reported to strongly affect the assembly of GO. The porosity structure is also difficult to control and depends on highly sensitive nanoscale phenomena. Most often, the authors claim the high performance of their materials also well supported by the shown results in term of adsorption capacity, specific capacitance etc. The reported results are rarely compared with less expensive materials such as typical activated carbons. Many of these GBMs are, however, much more costly than activated carbons and therefore the new investigation strategies are required to develop new approaches that enable the surface area and pore interconnectivity to be maximized together without reducing the mechanical properties.

Table 1 BET surface, porosity and density and applications of GBMs prepared by different methods

\begin{tabular}{|c|c|c|c|c|c|c|c|}
\hline Type of 3D GBMs & $\begin{array}{l}\text { Synthesis } \\
\text { approach }\end{array}$ & $\begin{array}{l}\text { Precursor/starting 2D } \\
\text { material/reactants }\end{array}$ & $\begin{array}{l}\text { BET } \\
\text { surface } \\
\text { area } \\
\left(\mathrm{m}^{2} \mathrm{~g}^{-1}\right)\end{array}$ & Porosity & $\begin{array}{l}\text { Density } \\
\left(\mathrm{g} \mathrm{cm}^{-3}\right)\end{array}$ & Application & Ref. \\
\hline \multicolumn{8}{|c|}{ Direct synthesis approach } \\
\hline $\begin{array}{l}\text { 3D highly porous } \\
\text { graphene }\end{array}$ & $\begin{array}{l}\text { Single-step } \\
\text { chemical } \\
\text { solid } \\
\text { deposition }\end{array}$ & $\begin{array}{l}\text { Carbon source: methane } \\
\text { Catalyst precursor: scallop } \\
\text { Etching solution: } \mathrm{HCl}\end{array}$ & 2720 & $\begin{array}{l}\text { Pore volume: } \\
1.45 \mathrm{~cm}^{3} \mathrm{~g}^{-1}\end{array}$ & $\mathrm{~N} / \mathrm{A}$ & $\begin{array}{c}\text { Methane } \\
\text { adsorption }\end{array}$ & 154 \\
\hline 3D porous FLG & $\begin{array}{l}\text { Direct CVD } \\
\text { growth by } \\
\text { porous Cu } \\
\text { template }\end{array}$ & $\begin{array}{l}\text { Catalyst precursor: Copper } \\
\text { carbonate } \\
\text { Etching solution: } \mathrm{HCl} \text { and } \\
\text { hydrogen peroxide }\left(\mathrm{H}_{2} \mathrm{O}_{2}\right)\end{array}$ & 1545 & $\begin{array}{l}\text { Pore volume: } \\
7.30 \mathrm{~cm}^{3} \mathrm{~g}^{-1}\end{array}$ & $\mathrm{~N} / \mathrm{A}$ & $\begin{array}{l}\text { Electrochemical } \\
\text { energy storage }\end{array}$ & 155 \\
\hline 3D graphene foams & $\begin{array}{l}\text { CVD growth } \\
\text { of graphene } \\
\text { films }\end{array}$ & $\begin{array}{l}\text { Carbon source: Methane } \\
\text { Catalyst precursor: Nickel } \\
\text { foam } \\
\text { Etching solution: } \mathrm{HCl} \text { and } \\
\mathrm{FeCl}_{3}\end{array}$ & $\sim 850$ & $\mathrm{~N} / \mathrm{A}$ & $\begin{array}{l}0.0025- \\
0.007\end{array}$ & $\mathrm{~N} / \mathrm{A}$ & 82 \\
\hline 3D graphene foams & $\begin{array}{l}\text { CVD growth } \\
\text { of graphene } \\
\text { foam }\end{array}$ & $\begin{array}{l}\text { Carbon source: ethanol } \\
\text { Catalyst precursor: GA } \\
\text { Etching solution: } \mathrm{HCl}\end{array}$ & $\sim 850$ & $\mathrm{~N} / \mathrm{A}$ & $\mathrm{N} / \mathrm{A}$ & $\begin{array}{c}\text { Supercapacitor } \\
\text { and enzymeless } \\
\text { glucose } \\
\text { detection }\end{array}$ & 88 \\
\hline
\end{tabular}




\begin{tabular}{|c|c|c|c|c|c|c|c|}
\hline $\begin{array}{l}\text { 3D graphene } \\
\text { nanowalls }\end{array}$ & PECVD & $\begin{array}{l}\text { Carbon source: methane } \\
\text { Catalyst precursor: GA }\end{array}$ & 795 & $\begin{array}{l}\text { Pore size: } \\
0.56-0.62 \mathrm{~nm}\end{array}$ & $\mathrm{~N} / \mathrm{A}$ & $N / A$ & 160 \\
\hline $\begin{array}{l}\text { 3D graphene } \\
\text { macroscopic objects }\end{array}$ & $\begin{array}{l}\text { Direct CVD } \\
\text { growth of } \\
\text { graphene } \\
\text { nanosructure }\end{array}$ & $\begin{array}{l}\text { Carbon source: methane } \\
\text { Catalyst precursor: nickel } \\
\text { chloride hexahydrate } \\
\text { Etching solution: } \mathrm{HCl} \text { and } \\
\mathrm{FeCl}_{3}\end{array}$ & $\sim 560$ & $N / A$ & 0.022 & $\begin{array}{l}\text { Removal of } \\
\text { heavy metal }\end{array}$ & 161 \\
\hline 3D graphene foams & $\begin{array}{l}\text { Direct CVD } \\
\text { growth by } \\
\text { seashell } \\
\text { based } \\
\text { templete }\end{array}$ & $\begin{array}{l}\text { Catalyst precursor: bagasse } \\
\text { Etching solution: } \mathrm{HCl}\end{array}$ & 337 & $\begin{array}{l}\text { Pore size: } \\
2.3-3.6 \mathrm{~nm}\end{array}$ & 0.03 & $\begin{array}{l}\text { Oil- water } \\
\text { separation }\end{array}$ & 162 \\
\hline \multicolumn{8}{|c|}{ Self-assembly approach } \\
\hline 3D porous graphene & $\begin{array}{l}\text { Self- } \\
\text { assembly by } \\
\text { hydrothermal } \\
\text { reduction } \\
\text { and chemical } \\
\text { activation }\end{array}$ & $\begin{array}{l}\text { Starting material: GO } \\
\text { Type of Linker: phenol and } \\
\text { formaldehyde / PVA } \\
\text { Chemical activation: } \mathrm{KOH}\end{array}$ & 3523 & $\mathrm{~N} / \mathrm{A}$ & $\mathrm{N} / \mathrm{A}$ & Supercapacitors & 156 \\
\hline $\begin{array}{l}\text { 3D graphene } \\
\text { hydrogel }\end{array}$ & $\begin{array}{l}\text { Self- } \\
\text { assembly by } \\
\text { hydrothermal } \\
\text { reduction }\end{array}$ & $\begin{array}{l}\text { Starting material: GO } \\
\text { Reductant: hydrazine } \\
\text { monohydrate } \\
\text { Starting material: GO } \\
\text { Reductant: ethyl- } \\
\text { enediamine } \\
\text { Starting material: GO } \\
\text { Reductant: 1, 4- } \\
\text { diaminobutane }\end{array}$ & 677 & $\begin{array}{l}\text { Pore size: } 13- \\
25 \mathrm{~nm}\end{array}$ & $\mathrm{~N} / \mathrm{A}$ & Supercapacitors & 126 \\
\hline 3D porous graphene & $\begin{array}{l}\text { Self- } \\
\text { assembly by } \\
\text { mechanical } \\
\text { exfoliation } \\
\text { and chemical } \\
\text { activation }\end{array}$ & $\begin{array}{l}\text { Starting material: } \mathrm{rGO} \\
\text { Chemical activation: } \mathrm{KOH}\end{array}$ & $\begin{array}{l}\sim 1000- \\
3000\end{array}$ & $\begin{array}{l}\text { Pore volume: } \\
1-2.4 \mathrm{~cm}^{3} \mathrm{~g}^{-1} \\
\text { Pore size: }<2 \\
\mathrm{~nm}\end{array}$ & $\sim 0.1$ & $\begin{array}{c}\text { Supercapacitors } \\
\text { electrode }\end{array}$ & 157 \\
\hline 3D porous graphene & $\begin{array}{l}\text { Self- } \\
\text { assembly by } \\
\text { hydrothermal } \\
\text { reduction } \\
\text { and polymer } \\
\text { cross-linking }\end{array}$ & $\begin{array}{l}\text { Starting material: } \mathrm{GO} \\
\text { Type of linker: } \\
\text { Polyethylenimine (PEI) } \\
\text { Reductant: sodium } \\
\text { hydroxide }(\mathrm{NaOH})\end{array}$ & 476 & $\begin{array}{l}\text { Pore volume: } \\
0.6-1.3 \mathrm{~cm}^{3} \mathrm{~g}^{-1}\end{array}$ & $0.02-0.03$ & $\begin{array}{l}\text { Dye and gas } \\
\text { adsorption }\end{array}$ & 163 \\
\hline $\begin{array}{l}\text { 3D graphene-based } \\
\text { macrostructures }\end{array}$ & $\begin{array}{l}\text { Self- } \\
\text { assembly by } \\
\text { hydrothermal } \\
\text { reduction } \\
\text { and chemical } \\
\text { activation }\end{array}$ & $\begin{array}{l}\text { Starting material: } \mathrm{GO} \\
\text { Chemical activation: } \mathrm{CO}_{2}\end{array}$ & $\sim 1300$ & $\begin{array}{l}\text { Pore volume: } \\
>1 \mathrm{~cm}^{3} \mathrm{~g}^{-1}\end{array}$ & $\mathrm{~N} / \mathrm{A}$ & $\begin{array}{l}\text { Gas adsorption } \\
\left.\text { ( } \mathrm{CO}_{2} \text { capture }\right)\end{array}$ & 158 \\
\hline $\begin{array}{l}\text { 3D nitrogen doped } \\
\text { GA }\end{array}$ & $\begin{array}{l}\text { Self- } \\
\text { assembly by } \\
\text { thermal } \\
\text { process }\end{array}$ & $\begin{array}{l}\text { Starting material: GO } \\
\text { Reductant: ammonia } \\
\text { solution }\end{array}$ & 830 & $\begin{array}{l}\text { Pore volume: } \\
0.05-0.3 \mathrm{~cm}^{3} \mathrm{~g}^{-1} \\
\text { Pore size: } \\
3.9 \mathrm{~nm}\end{array}$ & $\mathrm{~N} / \mathrm{A}$ & $\begin{array}{l}\text { Supercapacitors } \\
\text { electrode and } \\
\text { gas adsorption }\end{array}$ & 120 \\
\hline 3D porous graphene & $\begin{array}{l}\text { Self- } \\
\text { assembly by } \\
\text { polymer } \\
\text { cross-linking }\end{array}$ & $\begin{array}{l}\text { Starting material: rGO } \\
\text { Type of linker: 1,4- } \\
\text { diethynylbenzene and 4,4- } \\
\text { diethynylbiphenyl } \\
\text { Reductant: } \mathrm{NaBH}_{4}\end{array}$ & 825 & $\begin{array}{l}\text { Pore volume: } \\
0.74 \mathrm{~cm}^{3} \mathrm{~g}^{-1} \\
\text { Pore size: } 1.5- \\
4.0 \mathrm{~nm}\end{array}$ & $\mathrm{~N} / \mathrm{A}$ & Gas storage & 164 \\
\hline 3D GA & $\begin{array}{l}\text { Self- } \\
\text { assembly by } \\
\text { hydrothermal } \\
\text { reduction }\end{array}$ & Starting material: GO & 722 & $\begin{array}{l}\text { Pore size: } 0.56 \\
\mathrm{~nm}\end{array}$ & $N / A$ & $N / A$ & 160 \\
\hline
\end{tabular}




\section{D glucose / graphene-based aerogels}

3D GO composite

3D GA

3D porous $G O$ membrane

3D graphene

3D lignosulfonategraphene porous hydrogel

3D nanoporous graphene

3D nitrogen doped GA

3D porous graphene foam

3D copolymer/ GA

3D graphene composites

3D graphene hydrogel

3D N-Doped GA

3D GA
Self-

assembly by Starting material: GO

hydrothermal Type of Linker: glucose

and chemical Chemical activation: $\mathrm{CO}_{2}$

activation

Self-

assembly via Type of linker:

chemical

cross-linking

Self-

assembly by

chemical

function

grafting

Selfassembly by organic and polymer cross-linking

Self-

assembly by

thermal

process

Self-

assembly via

polymer

cross-linking

Self-

assembly by

chemical

reduction

Self-

assembly by

thermal

process

Self-

assembly by hydrothermal

reduction

and polymer

cross-linking

Self-

assembly by

hydrothermal

reduction

and polymer

cross-linking

Self-

assembly via

chemical

cross-linking

Self-

assembly via

chemical

cross-linking

Self-

assembly by Starting material: GO solvothermal reduction

Selfassembly by glutaraldehyde, resorcinol

and Borax

Starting material: GO

Type of linker:

lignosulfonate

Functional group: amine

Starting material: GO

Type of organic linker: nisin antimicrobials peptide

Type of polymer: EDC and

PEG

Starting material: GO

477

Starting material: GO

Type of linker:

lignosulfonate

Reductant: vitamin C

Starting material: GO

Reductant: hydriodic acid

(HI)

Starting material: GO

Reductant: concentrated

ammonium hydroxide

Starting material: GO

Type of linker: PVA

Reductant: urea

Starting material: GO

Type of linker: Composite flocculant P(AM-DMDAAC)

Reductant: urea

Starting material: GO

Type of linker:

tetraethylenepentamine

(TEPA)

Starting material: GO

Type of linker: PEI

Type of linker: EDA

Starting material: GO

Type of reductant: gallic acid, gentisic acid,

627
Pore volume:

$3.06 \mathrm{~cm}^{3} \mathrm{~g}^{-1}$

Pore size:

$\mathrm{N} / \mathrm{A}$

$16.04 \mathrm{~nm}$

Supercapacitors

and gas

adsorption

Gas storage

$\sim 700 \quad \mathrm{~N} / \mathrm{A}$

$0.02-0.03$

and adsorption

$\left(\mathrm{CO}_{2}\right.$ capture $)$

Pore size:

1 to $40 \mathrm{~nm}$

$\mathrm{N} / \mathrm{A}$

Removal of

heavy metal

Water and

Pore volume:

$0.380 \mathrm{~cm}^{3} \mathrm{~g}^{-1}$

Pore size:

N/A

wastewater

treatment

(disinfection of

multiple drug

resistant)

Gases and

Pore volume:

$1.04 \mathrm{~cm}^{3} \mathrm{~g}^{-1}$

$\mathrm{N} / \mathrm{A}$

water vapor

adsorption

$473.5 \quad \mathrm{~N} / \mathrm{A}$

$\mathrm{N} / \mathrm{A}$

Removal of

heavy metal

Pore volume:

$0.42 \mathrm{~cm}^{3} \mathrm{~g}^{-1}$

Pore size: $<2$

Gas adsorption

$\mathrm{nm}$

235.95

Pore size:

$3.87 \mathrm{~nm}$

$\mathrm{N} / \mathrm{A}$

Microbial fuel cells

210.37

Pore size:

$41.1 \mathrm{~nm}$

N/A

Supercapacitors

172

$206.591 \quad 3.6-4.2 \mathrm{~nm}$

0.0114

Oil/water separation

194.48

Pore volume: $0.042 \mathrm{~cm}^{3} \mathrm{~g}^{-1}$

N/A

Gas adsorption $\left(\mathrm{CO}_{2}\right.$ capture)

Pore volume:

$0.152 \mathrm{~cm}^{3} / \mathrm{g}$

Pore size:

N/A

Extraction of uranium

$2.19 \mathrm{~nm}$

N/A

0.01

Gas adsorption ( $\mathrm{CO}_{2}$ capture)

Pore size: 3-5 $\mu \mathrm{m}$

Sensing device 


\begin{tabular}{|c|c|c|c|c|c|c|}
\hline & $\begin{array}{l}\text { hydrothermal } \\
\text { reduction }\end{array}$ & $\begin{array}{l}\text { protocatechuic acid, vanillic } \\
\text { acid and ferulic acid }\end{array}$ & & & & \\
\hline $\begin{array}{l}\text { 3D graphene } \\
\text { composite }\end{array}$ & $\begin{array}{l}\text { Self- } \\
\text { assemble } \\
\text { with organic } \\
\text { linker }\end{array}$ & $\begin{array}{l}\text { Starting material: GO Type } \\
\text { of organic linker: } \beta \text { - } \\
\text { cyclodextrin/poly (I-glutamic } \\
\text { acid) }\end{array}$ & 105.50 & - & $\mathrm{N} / \mathrm{A}$ & $\begin{array}{l}\text { Water and } \\
\text { wastewater } \\
\text { treatment }\end{array}$ \\
\hline 3D GA & $\begin{array}{l}\text { Chemical } \\
\text { reduction }\end{array}$ & $\begin{array}{l}\text { Starting material: GO } \\
\text { Type of reductant: Gallic } \\
\text { acid, gentisic acid, } \\
\text { protocatechuic acid, vanillic } \\
\text { acid and ferulic acid }\end{array}$ & $\begin{array}{l}100- \\
350\end{array}$ & $\begin{array}{l}\text { Pore volume: } \\
0.0132 \mathrm{~cm}^{3} \mathrm{~g}^{-1}\end{array}$ & $\begin{array}{l}0.0132- \\
0.0177\end{array}$ & $\begin{array}{l}\text { Wastewater } \\
\text { treatment }\end{array}$ \\
\hline $\begin{array}{l}\text { Graphene/cysteamine } \\
\text { aerogel }\end{array}$ & $\begin{array}{l}\text { Self- } \\
\text { assemble } \\
\text { with organic } \\
\text { linker } \\
\text { Self- } \\
\text { assemble }\end{array}$ & $\begin{array}{l}\text { Starting material: GO } \\
\text { Type of organic linker: } \\
\text { cysteamine }\end{array}$ & 68.11 & $\mathrm{~N} / \mathrm{A}$ & $N / A$ & $\begin{array}{c}\text { Water } \\
\text { purification }\end{array}$ \\
\hline 3D GO composite & $\begin{array}{l}\text { with } \\
\text { chemical } \\
\text { cross-linking }\end{array}$ & $\begin{array}{l}\text { Type of linker: alginate } \\
\text { beads with calcium chloride }\end{array}$ & 60 & 0.1 & $\mathrm{~N} / \mathrm{A}$ & Dye removal \\
\hline
\end{tabular}

Key factors to control 2D graphene self-assembly to 3D GBMs. As described in previous sections, in most of the approaches to design 3D GBMs, GO is used as the starting graphene materials and its chemical modification especially by ionization and/or reduction resulting in lessen the repulsive forces between in the graphene nanosheets inducing their self-assembly in a more or less controlled manner. The control of the graphene intersheet interactions which are the driving force for the selfassembly phenomenon and potentially avoid or limit the $2 \mathrm{D}$ graphene restacking in order to maximize the porosity of the prepared 3D GBMs is one of the main objectives of the field. As mentioned earlier, the self-assembly process is very sensitive to the experimental conditions used (temperature graphene concentration, drying process) and to the characteristics of graphene (size and shape, thickness, surface chemistry) which both have a significant impact on the resulting properties of $3 D$ GBMs. The influence of the GO nanosheet characteristics is difficult to study and rarely found in the literature. However, it was shown that a higher oxygen content and a larger contribution from $\mathrm{C}-\mathrm{OH} / \mathrm{C}-\mathrm{O}-\mathrm{C}$ of the $\mathrm{GO}$ used could lead to a better porosity by using a solvothermal/freeze-drying process to prepare 3D GBMs 180. The concentration of GO in solution is another important factor influencing the morphological properties of 3D GBMs. Zhou et al. showed that an optimized concentration of $6 \mathrm{mg} \mathrm{mL}^{-1}$ of GO lead to a uniform pore size distribution and the highest specific surface area (SSA) from BET analysis, i.e. $795 \mathrm{~m}^{2} \mathrm{~g}^{-1}$, for the $2-10 \mathrm{mg} \mathrm{mL}^{-}$ ${ }^{1} \mathrm{GO}$ concentration range investigated ${ }^{160}$. In their work, they also pointed out the importance of the last step of 3D GBM preparation: freeze-drying. Using tert-butanol was found to be a better method thanks to a lower surface tension of tert-butanol butanol compared to water. Since $\mathrm{GO}$ bears $\mathrm{COOH}$ groups, modification of $\mathrm{pH}$, for example by varying the $\mathrm{pH}$ in the 5.5-11.7 range by ammonia addition in the work from $\mathrm{Bi}$ et al. was shown to have a direct impact on both structural and electrical and mechanical properties of the prepared 3D GBMs ${ }^{181}$. pH 10 was found to be an optimized $\mathrm{pH}$. Electrostatic attractive forces were also used to provoke GO nanosheet (negatively charged) assembly by adding cationic polystyrene (PS) microspheres and forming 3D PS/GO core-shell materials ${ }^{102}$. In another work, the self-assembly process of GO in a mixture of isopropanol and water was better controlled at $\mathrm{pH} 2{ }^{182}$. In this work, the reduction of GO was induced by $\gamma$-ray radiations. Temperature and thermal treatments are as well usually seen as one of the main contributing factors in the 3D GBM preparation methods, particularly in hydrothermal self-assembly, as it has been shown to have a significant impact on the GO surface chemistry and also on the final properties of the prepared aerogels. ${ }^{175}$. The use of bubbles created by boiling a rGO solution was reported as a simple and efficient method to control the structural properties of 3D GBMs ${ }^{183}$. By using the appropriate heat flux for the bubbling, 3D GBMs having a controlled porous structure with a high Young's modulus were obtained. Apart from the control of GO surface chemistry or the self-assembly process by modifying the experimental conditions, the use of linkers such as L-cysteine ${ }^{135}$ or dimethyldiallylammonium chloride acrylamide polymer (P(AMDMDAAC)) ${ }^{173}$ was shown to be efficient to control the structure of $3 D$ GBMs. Moreover, templates allow also to prepare pure graphene or hybrid graphene 3D GBMs with specific properties and dedicated to specific applications. Ni foam could be used as template in which a rGO solution was deposited ${ }^{184}$. By optimizing the rGO concentration, the authors could prepare graphene/ $\mathrm{Ni}$ electrodes with high capacitance. In other works, the porosity of 3D GBMs was controlled by using nanoparticles of cobalt oxides $\left(\mathrm{Co}_{3} \mathrm{O}_{4}\right)^{185}$ or palladium ${ }^{186}$ and the induced carbothermal reaction was responsible for the formation of a porous structure. By modifying the size of the metal- based nanoparticles, the resulting pore size within the 3D GBMs was modified. Microemulsions can also be efficiently used to prepare 3D GBMs of controlled pore size by adjusting the microemulsion droplet size (GO/cyclohexane ratio) and the $\mathrm{pH}^{187}$. In a comparable approach, polystyrene (PS) charged nanobeads were used to control the size of the internal porosity of GA ${ }^{188}$.

\section{Summary and outlook}

The 3D GBMs show interesting properties and they are especially very promising materials for applications where the surface exchanges play the major role. The fields of interest for these innovative nanostructured materials cover especially energy technology (conversion and storage), environmental $\left(\mathrm{CO}_{2}\right.$ capture and water treatment) and catalysis. However, the large- 
scale transfer is not yet possible at this stage, several issues are still to be overcome.

At the current stage of 3D GBM development, among all the described approaches, it is not clear which one leads to the best material in term of surface and physical properties. Further fundamental investigations are needed in order to control and enhance both the preparation methods and the performance of these 3D GBMs. The chemistry and the interaction forces involved in the self-assembly processes are not well understood yet. The chemical procedures successfully applied to other carbon family, such as fullerenes and CNTs could be a comprehensive reference to further emerging the graphene functionalization concepts to develop 3D GBMs. Unfortunately, they cannot be directly transferred to graphene because chemical reactivity of graphene (GO, rGO, FLG, GNP...) is different to that of fullerenes and CNTs which have both a curved $\mathrm{sp}^{2}$ network. Theoretical/calculation tools are rarely used to study GBMs and the mechanisms involved in their preparation. Such approach could help to identify the interactions between the 2D graphene nanosheets and the parameters which play the major role to control them. Furthermore, combining experimental and theoretical investigations could provide the crucial in-depth understanding of the self-assembly mechanisms to go further in developing 3D GBMs in the future.

As we have seen in this review, the approaches are mainly based on i) CVD deposition of interconnected graphene using a template and ii) self-assembly of $\mathrm{GO} / \mathrm{rGO}$. Due to the low pressure and high temperature ranges used, low cost production of GBMs by CVD is limited. Regarding the self-assembly route from GO, the presence of many defects/functional groups at the graphene surface induces poor assembly mechanism control and restacking which leads to low and/or non-reproducible performances. Other kind of graphene materials, such as FLGs or GNPs prepared by mechanical exfoliation are poorly investigated to prepare GBMs. Even if such kind of graphene requires a post-synthesis chemical treatment, their controlled chemical functionalization could allow to better master the selfassembly process and contribute to a better knowledge of the assembly mechanisms involved in GBMs.

\section{Acknowledgements}

The authors thanked French Ambassy in Malaysia for financial support especially for Ms. R. Mohd Firdaus' Fellowship. Financial support for this study was also provided by Hubert Curien Partnership France-Malaysia Hibiscus (PHC Hibiscus) Grant from Ministry of Europe and Foreign Affairs (MEAE) and the French Ministry of National Education. We acknowledge the financial support given by the Ministry of Education Malaysia through Universiti Sains Malaysia Fellowship, Universiti Sains MalaysiaNanoMITE (203/PJKIMIA/6720009), and Institute of Postgraduate Studies Universiti Sains Malaysia.

Keywords: aerogel $\bullet$ graphene $\cdot$ porosity $\cdot$ self-assembly $\bullet$ 3D macrostructures

\section{References}

[1] L. Zhang, Q. Wei, J. An, L. Ma, K. Zhou, W. Ye, Z. Yu, X. Gan, C.-T. Lin, J. Luo, Chem. Eng. J. 2020, 380, 122551.

[2] M. Chen, R. Guan, S. Yang, Adv. Sci. 2019, 6, 1800941

[3] D. Janas, Sustainability 2020, 12, 4115.

[4] A.K. Geim, K.S. Novoselov, Nat. Mater. 2007, 6, 183-191.

[5] J.U. Arikpo, M.U. Onuu, J. Mater. Sci. Res. 2019, 8, 32.

[6] A.A. Balandin, S. Ghosh, W. Bao, I. Calizo, D. Teweldebrhan, F. Miao, C.N. Lau, Nano Lett. 2008, 8, 902-907.

[7] K.S. Novoselov, Sci. 2004, 306, 666-669.

[8] M. Rethinasabapathy, S.M. Kang, S.C. Jang, Y.S. Huh, Carbon Lett. 2017, 22, 1-13.

[9] H. Wang, X. Mi, Y. Li, S. Zhan, Adv. Mater. 2020, 32, 1806843.

[10] N. Yousefi, X. Lu, M. Elimelech, N. Tufenkji, Nature Nanotech. 2019, 14, 107-119.

[11] H. Pang, Y. Wu, X. Wang, B. Hu, X. Wang, Chem. Asian J. 2019, 14, 2542-2552.

[12] Y. Huang, Y.Tang, Y. Mai, X. Wang, C. Wang, S. Han, F. Zhang, D. Wu, X. Feng, Chem. Asian J. 2016, 11, 1194-1198.

[13] S. Venkateshalu, A. N. Grace, J. Electrochem. Soc. 2020, 167, 050509.

[14] L.Wang, X. Hu, Chem. Asian J. 2018, 13, 1518-1529.

[15] M. Wu, J. Liao, L. Yu, R. Lv, P. Li, W. Sun, R. Tan, X. Duan, L. Zhang, F. Li, J. Kim, K.H. Shin, H. Seok Park, W. Zhang, Z.Guo, H. Wang, Y. Tang, G. Gorgolis, C. Galiotis, J. Ma, Chem. Asian J. 2020, 15, 995-1013.

[16] O. Bagoole, M. Rahman, H. Younes, S. Shah, A. Al Ghaferi, J. Nanomed. Nanotechnol. 2017, 8.

[17] G. Gorgolis, C. Galiotis, 2D Materials 2017, 4, 032001.

[18] Z. Yuan, X. Xiao, J. Li, Z. Zhao, D. Yu, Q. Li, Adv. Sci. 2018, 5, 1700626.

[19] X. Zang, Q. Zhou, J. Chang, K.S. Teh, M. Wei, A. Zettl, L. Lin, Adv. Mater. Interfaces 2017, 4, 1600783.

[20] C.R. Herron, K.S. Coleman, R.S. Edwards, B.G. Mendis, J. Mater. Chem. 2011, 21, 3378

[21] H. Tan, D. Wang, Y. Guo, Materials 2019, 12, 2279

[22] N.I. Zaaba, K.L. Foo, U. Hashim, S.J. Tan, W.-W. Liu, C.H. Voon, Procedia Eng. 2017, 184,469-477.

[23] A.E. Awadallah, A.A. Aboul-Enein, U.F. Kandil, M.R. Taha, Mater. Chem. Phys. 2017, 191, 75-85.

[24] J. Hao, C. Huang, H. Wu, Y. Quu, Q. Gao, Z. Hu, E. Kan, L. Zhang, Nanoscale 2015, 7, 17096-17101.

[25] S.Y. Lee, D.L. Duong, Q.A. Vu, Y. Jin, P. Kim, Y.H. Lee, ACS Nano 2015, 9, 9034-9042.

[26] K. Kanayama, K. Nagashio, Sci. Rep. 2015, 5, 1-9.

[27] Y. Zhang, Q. Wan, N. Yang, Small 2019, 15, 1903780

[28] S. Mao, H. Pu, J. Chen, RSC Adv. 2012, 2, 2643

[29] A. Liang, X. Jiang, X. Hong, Y. Jiang, Z. Shao, D. Zhu, Coatings 2018, 8, 33.

[30] L. Rodríguez-Pérez, M.Á. Herranz, N. Martín, ChemComm. 2013, 49, 3721.

[31] W. Norimatsu, M. Kusunoki, Phys. Chem. Chem. Phys. 2014, 16, 3501.

[32] R.S. Edwards, K.S. Coleman, Nanoscale 2013, 5, 38-51.

[33] T. Mahmoudi, Y. Wang, Y.-B. Hahn, Nano Energy 2018, 47, 51-65.

[34] E.S. Polsen, D.Q. McNerny, B. Viswanath, S.W. Pattinson, A. John Hart, Sci. Rep. 2015, 5, 1-12.

[35] I. Lee, D.J. Bae, W.K. Lee, C.-M. Yang, S.W. Cho, J. Nam, D.Y. Lee, A.R. Jang, H.S. Shin, J.Y. Hwang, S. Hong, K.S. Kim, Carbon 2019, 145, 462-469.

[36] E.O. Polat, O. Balci, N. Kakenov, H.B. Uzlu, C. Kocabas, R. Dahiya, Sci. Rep. 2015, 5, 16744.

[37] S. Dayou, B. Vigolo, A. Desforges, J. Ghanbaja, A.R. Mohamed, J Nanopart Res. 2017, 19, 336.

[38] M. Choucair, P. Thordarson, J.A. Stride, Nat. Nanotechnol. 2009, 4, 3033.

[39] R. Wang, C. Xu, M. Du, J. Sun, L. Gao, P. Zhang, H. Yao, C. Lin, Small 2014, 10, 2260-2269

[40] X. Lu, M. Yu, H. Huang, R.S. Ruoff, Nanotechnology 1999, 10, 269-272.

[41] K.S. Novoselov, D. Jiang, F. Schedin, T.J. Booth, V.V. Khotkevich, S.V. Morozov, A.K. Geim, PNAS 2005, 102, 10451-10453.

[42] M.I. Kairi, S. Dayou, N.I. Kairi, S.A. Bakar, B. Vigolo, A.R. Mohamed, J. Mater. Chem. A 2018, 6, 15010-15026.

[43] Y. Lv, L. Yu, C. Jiang, S. Chen, Z. Nie, RSC Adv. 2014, 4, 13350

[44] B. Alinejad, K. Mahmoodi, Funct. Mater. Lett. 2017, 10, 1750047. 
[45] W. Deng, Q. Fang, X. Zhou, H. Cao, Z. Liu, RSC Adv. 2016, 6, 2084320849.

[46] C. Cheng, P. Jia, L. Xiao, J. Geng, Carbon 2019, 145, 668-676

[47] I.Y. Jeon, S.Y. Bae, J.M. Seo, J.B. Baek, Adv. Funct. Mater. 2015, 25 , 6961-6975.

[48] J. Xu, I.Y. Jeon, J.M. Seo, S. Dou, L. Dai, J.B. Baek, Adv. Mater. 2014 26, 7317-7323.

[49] I.Y. Jeon, H.J. Choi, S.M. Jung, J.M. Seo, M.J. Kim, L. Dai, J.B. Baek, JACS 2013, 135, 1386-1393.

[50] A. Pirzado, F. Le Normand, T. Romero, S. Paszkiewicz, V. Papaefthimiou, D. Ihiawakrim, I. Janowska, Chem. Eng. 2019, 3, 37.

[51] S. Haar, M. El Gemayel, Y. Shin, G. Melinte, M.A. Squillaci, O. Ersen, C. Casiraghi, A. Ciesielski, P. Samorì, Sci. Rep. 2015, 5, 16684.

[52] H. Iguchi, C. Higashi, Y. Funasaki, K. Fujita, A. Mori, A. Nakasuga, T. Maruyama, Sci. Rep. 2017, 7, 1-8.

[53] J. Hendrix, R. Szeto, T. Nosker, J. Lynch-Branzoi, T. Emge, Polymers 2018, 10, 1399.

[54] R.C. Sinclair, J.L. Suter, P.V. Coveney, Phys. Chem. Chem. Phys. 2019, 21, 5716-5722.

[55] M.A. Saiful Badri, M.M. Salleh, N.F. Md Noor, M.Y.A. Rahman, A.A Umar, Mater. Chem. Phys. 2017, 193, 212-219.

[56] Y.Z. Wang, T. Chen, H.H. Liu, X.C. Wang, X.X. Zhang, J. Nanosci. Nanotechnol. 2019, 19, 2078-2086.

[57] P.G. Karagiannidis, S.A. Hodge, L. Lombardi, F. Tomarchio, N. Decorde, S. Milana, I. Goykhman, Y. Su, S.V. Mesite, D.N. Johnstone, R.K. Leary, P.A. Midgley, N.M. Pugno, F. Torrisi, A.C. Ferrari, ACS Nano 2017, 11 2742-2755.

[58] R. Bhoria, Graphene and Its Derivatives - Synthesis and Applications: Enhancing Liquid Phase Exfoliation of Graphene in Organic Solvents with Additives 2019.

[59] K. Zhang, X. Zhang, H. Li, X. Xing, L. Jin, Q. Cao, P. Li, J. Mater. Sci. 2018, 53, 2484-2496.

[60] S. Wang, M. Yi, Z. Shen, RSC Adv. 2016, 6, 56705-56710.

[61] C. Vacacela Gomez, T. Tene, M. Guevara, G. Tubon Usca, D. Colcha, H. Brito, R. Molina, S. Bellucci, A. Tavolaro, Appl. Sci. 2019, 9, 2539.

[62] Zaw Lin, Paneer Karthik, Masaki Hada, Takeshi Nishikawa, Yasuhiko Hayashi, Nanomaterials 2017, 7, 125.

[63] K. R Paton, E. Varrla, C. Backes, R.J. Smith, U. Khan, A. O'Neill, T. Higgins, Nat. Mater. 2014, 13, 624-630.

[64] E. Varrla, K.R. Paton, C. Backes, A. Harvey, R.J. Smith, J. McCauley, J.N. Coleman, Nanoscale 2014, 6, 11810-11819.

[65] Y. Li, N. Chopra, JOM, 2015, 67, 34-43

[66] T.S. Tran, S.J. Park, S.S. Yoo, T.-R. Lee, T. Kim, RSC Adv. 2016, 6 , 12003-12008.

[67] J. Tian, L. Guo, X. Yin, W. Wu, Mater. Chem. Phys. 2019, 223, 1-8.

[68] M. Yi, Z. Shen, J. Mater. Chem. A 2015, 3, 11700-11715.

[69] D.R. Dreyer, S. Park, C.W. Bielawski, R.S. Ruoff, Chem. Soc. Rev. 2010, 39, 228-240.

[70] L. Staudenmaier, Rep. German. Chem. Soc. 1898, 31, 1481-1487.

[71] B. C. Brodie, Trans. R. Soc. London. 1859, 14, 249-259.

[72] W.S. Hummers, R.E. Offeman, J. Am. Chem. Soc. 1958, 80, 1339-1339.

[73] A.Y.S. Eng, C.K. Chua, M. Pumera, Nanoscale 2015, 7, 20256-20266.

[74] P.P. Brisebois, M. Siaj, J. Mater. Chem. C 2020, 8, 1517-1547.

[75] S. Thakur, N. Karak, Carbon 2015, 94, 224-242.

[76] S. Eigler, S. Grimm, M. Enzelberger-Heim, P. Müller, A. Hirsch, Chem. Commun. 2013, 49, 7391.

[77] S. Rattan, S. Kumar, J.K. Goswamy, Mater. Today. Proc. 2020, 26, 3327 3331.

[78] Z. Yang, S. Chabi, Y. Xia, Y. Zhu, Pro Nat Sci-Mater. 2015, 25, 554-562.

[79] R. Kumar, R.K. Singh, A.R. Vaz, R. Savu, S.A. Moshkalev, ACS Appl. Mater. Interfaces 2017, 9, 8880-8890.

[80] K. Spilarewicz-Stanek, A. Kisielewska, J. Ginter, K. Bałuszyńska, I. Piwoński, RSC Adv. 2016, 6, 60056-60067.

[81] Y. Liu, C. Guo, D. Zhang, Y. Shang, Mater. Lett. 2014, 115, 25-28.

[82] Z. Chen, W. Ren, L. Gao, B. Liu, S. Pei, H.-M. Cheng, Nat. Mater, 2011, 10, 424-428.

[83] Y. Hoshi, J. Takahashi, H. Wang, H. Kato, Y. Homma, Surf. Sci. 2018 $670,72-75$

[84] Y. Chen, X. Zhang, E. Liu, C. He, Y. Han, Q. Li, P. Nash, N. Zhao, J Alloy Compd. 2016, 688, 69-76.
[85] H.-A. Mehedi, B. Baudrillart, D. Alloyeau, O. Mouhoub, C. Ricolleau, V.D. Pham, C. Chacon, A. Gicquel, J. Lagoute, S. Farhat, J Appl Phys. 2016, 120, 065304.

[86] H. Wang, Z. Xiong, S. Jin, C. Qing, Fuller Nanotub Car N. 2019, 27, 823829.

[87] G. Ning, Z. Fan, G. Wang, J. Gao, W. Qian, F. Wei, Chem Commun. 2011, 47, 5976

[88] X.-C. Dong, H. Xu, X.-W. Wang, Y.-X. Huang, M.B. Chan-Park, H. Zhang L.-H. Wang, W. Huang, P. Chen, ACS Nano 2012, 6. 3206-3213.

[89] X. Hu, T. Huang, Y. Tang, G. Fu, J.-M. Lee, ACS Appl. Mater. Interfaces. 2019, 11, 4028-4036.

[90] G. Fu, X. Yan, Y. Chen, L. Xu, D. Sun, J.-M. Lee, Y. Tang, Adv. Mater 2018, 30, 1704609.

[91] A. Jayakumar, Y.-J. Yoon, R. Wang, J.-M. Lee, RSC Adv. 2015, 5, 94388-94396.

[92] A. Jayakumar, R.P. Antony, R. Wang, J.-M. Lee, Small. 2017, 13, 1603102.

[93] R. Wang, A. Jayakumar, C. Xu, J.-M. Lee, ACS Sustain. Chem. Eng 2016, 4, 3736-3742

[94] R. Wang, C. Xu, J.-M. Lee, Nano Energy 2016, 19, 210-221.

[95] Y. Ma, H. Jang, S.J. Kim, C. Pang, H. Chae, Nanoscale Res. Lett. 2015, 10, 1-8.

[96] J. Zeng, X. Ji, Y. Ma, Z. Zhang, S. Wang, Z. Ren, C. Zhi, J. Yu, Adv. Mater. 2018, 30, 1705380 .

[97] H.-F. Li, F. Wu, C. Wang, P.-X. Zhang, H.-Y. Hu, N. Xie, M. Pan, Z. Zeng S. Deng, M. Wu, K. Vinodgopal, G.-P. Dai, Nanomaterials 2018, 8, 700.

[98] S. Ansari, A. Kelarakis, L. Estevez, E.P. Giannelis, Small, 2010, 6, 205209.

[99] B. Li, G. Pan, N.D. Avent, R.B. Lowry, T.E. Madgett, P.L. Waines, Biosens. Bioelectron. 2015, 72, 313-319.

[100] J. Filip, J. Tkac, Electrochem. commun. 2014, 49, 70-74.

[101] Z. Xu, J. Jiang, Q. Zhang, G. Chen, L. Zhou, L. Li, Colloid Interface Sci. 2020, 563, 131-138.

[102] Y. Li, Y. Xu, T. Zhou, A. Zhang, J. Bao, RSC Adv. 2015, 5, 32469-32478.

[103] R. Zhao, K. Li, R. Liu, M. Sarfraz, I. Shakir, Y. Xu, J. Mater. Chem. A 2017, 5, 19098-19106.

[104] S.H. Lee, H.W. Kim, J.O. Hwang, W.J. Lee, J. Kwon, C.W. Bielawski, R.S. Ruoff, S.O. Kim, Angew. Chem. Int. Ed. 2010, 49, 10084-10088.

[105] K. Chen, L. Chen, Y. Chen, H. Bai, L. Li, J. Mater. Chem. 2012, 22, 20968.

[106] M. Mirzaee, C. Dehghanian, K. Sabet Bokati, J. Electroanal. Chem. 2018 $813,152-162$.

[107] H. Yan, J. Bai, B. Wang, L. Yu, L. Zhao, J. Wang, Q. Liu, J. Liu, Z. Li, Electrochim. Acta. 2015, 154, 9-16.

[108] J. Chen, J. Wu, H. Ge, D. Zhao, C. Liu, X. Hong, Compos. Part A Appl. Sci. Manuf. 2016, 82, 141-150.

[109] L. Sansone, V. Malachovska, P. La Manna, P. Musto, A. Borriello, G. De Luca, M. Giordano, Sensor Actuat B-Chem. 2014, 202, 523-526.

[110] M.-S. Wu, Y.-J. Zheng, Phys. Chem. Chem. Phys. 2013, 15, 1782-1787.

[111] X. Hui, L. Qian, G. Harris, T. Wang, J. Che, Mater. Des. 2016, 109, 242250.

[112] Y.B. Tan, J.-M. Lee, J. Mater. Chem. A. 2013, 1, 14814.

[113] B. Chang, J. Chen, M. Zhou, X. Zhang, W. Wei, B. Dai, S. Han, Y. Huang, Chem. Asian J. 2018, 13, 3859-3864.

[114] E. García-Bordejé, S. Víctor-Román, O. Sanahuja-Parejo, A.M. Benito, W.K. Maser, Nanoscale 2018, 10, 3526-3539.

[115] Y. Xu, K. Sheng, C. Li, G. Shi, ACS. Nano 2010, 4, 4324-4330.

[116] Y. Xu, G. Shi, X. Duan, Acc. Chem. Res. 2015, 48, 1666-1675.

[117] E. Chitanu, C. Banciu, G. Sbarcea, V. Marinescu, A. Bara, P. Barbu (Prioteasa), Rev. de Chim. 2019, 69, 3376-3381.

[118] Y. Yang, T. Liu, X. Zhu, F. Zhang, D. Ye, Q. Liao, Y. Li, Adv. Sci. 2016, 3, 1600097

[119] D. Long, W. Li, L. Ling, J. Miyawaki, I. Mochida, S.-H. Yoon, Langmuir. 2010, 26, 16096-16102.

[120] Z.-Y. Sui, Y.-N. Meng, P.-W. Xiao, Z.-Q. Zhao, Z.-X. Wei, B.-H. Han, ACS Appl. Mater. Interfaces 2015, 7, 1431-1438.

[121] B. Quan, S.-H. Yu, D.Y. Chung, A. Jin, J.H. Park, Y.-E. Sung, Y. Piao Sci. Rep. 2015, 4,1-6.

[122] Y. Lin, F. Liu, G. Casano, R. Bhavsar, I.A. Kinloch, B. Derby, Adv. Mater 2016, 28, 7993-8000

[123] R. Zhang, Y. Cao, P. Li, X. Zang, P. Sun, K. Wang, M. Zhong, J. Wei, D. Wu, F. Kang, H. Zhu, Nano. Res. 2014, 7, 1477-1487. 
[124] V. Rodríguez-Mata, J.M. González-Domínguez, A.M. Benito, W.K. Maser, E. García-Bordejé, ACS. Appl. Nano Mater. 2019, 2, 1210-1222.

[125] Z. Sui, X. Zhang, Y. Lei, Y. Luo, Carbon 2011, 49, 4314-4321.

[126] H. Banda, D. Aradilla, A. Benayad, Y. Chenavier, B. Daffos, L. Dubois, F. Duclairoir, J. Power. Sources. 2017, 360, 538-547.

[127] J. Gao, F. Liu, Y. Liu, N. Ma, Z. Wang, X. Zhang, Chem. Mater. 2010, 22 2213-2218.

[128] K. Sheng, Y. Xu, C. Li, G. Shi, New. Carbon. Mater. 2011, 26, 9-15.

[129] S. Pei, H.-M. Cheng, Carbon 2012, 50, 3210-3228.

[130] Z. Yang, Q. Zheng, H. Quu, J. Li, J. Yang, New. Carbon. Mater. 2015, 30, 41-47.

[131] L. Zhang, G. Chen, M.N. Hedhili, H. Zhang, P. Wang, Nanoscale 2012, 4, 7038.

[132] W. Chen, L. Yan, Nanoscale 2011, 3, 3132.

[133] C. Shao, Y. Zhao, L. Qu, Chem. Nano. Mat. 2020, 6, 1028-1048.

[134] B. Zhang, J. Zhang, X. Sang, C. Liu, T. Luo, L. Peng, B. Han, X. Tan, X. Ma, D. Wang, N. Zhao, Sci. Rep. 2016, 6, 25830.

[135] X. Zhang, D. Liu, L. Yang, L. Zhou, T. You, J. Mater. Chem. A 2015, 3 10031-10037.

[136] S. Chidambaram, G.M. Kumar, P. Ilanchezhiyan, R. Maheswaran, T.W. Kang, Mater. Lett. 2017, 191, 165-168.

[137] X. Zhang, D. Liu, L. Yang, L. Zhou, T. You, J. Mater. Chem. A 2015, 3, 10031-10037.

[138] Q. Fang, X. Zhou, W. Deng, Z. Liu, Nanoscale 2016, 8, 197-203.

[139] S. Mukhopadhyay, S. Batra, Eur. J. Org. Chem. 2019, 6424-6451.

[140] M. Moussa, M.F. El-Kady, D. Dubal, T.T. Tung, M.J. Nine, N. Mohamed, R.B. Kaner, D. Losic, ACS. Appl. Energy. Mater. 2020, 3, 923-932.

[141] X. Wang, Q. Liu, J. Liu, R. Chen, H. Zhang, R. Li, Z. Li, J. Wang, Appl. Surf. Sci. 2017, 426, 1063-1074.

[142] X. Shen, H. Du, R.H. Mullins, R.R. Kommalapati, Energy. Technol. 2017, $5,822-833$.

[143] Y. Xu, Q. Wu, Y. Sun, H. Bai, G. Shi, ACS. Nano 2010, 4, 7358-7362.

[144] X. Guo, L. Qu, M. Tian, S. Zhu, X. Zhang, X. Tang, K. Sun, Water. Environ Res. 2016, 88, 579-588.

[145] G. Zhang, F. Wang, J. Dai, Z. Huang, Materials 2016, 9, 92.

[146] S.K. Yadav, J.W. Cho, Appl. Surf. Sci. 2013, 266, 360-367.

[147] T. Hu, I. Baxendale, M. Baumann, Molecules 2016, 21, 918.

[148] N. Alzate-Carvajal, D.A. Acevedo-Guzmán, V. Meza-Laguna, M.H. Farías, L.A. Pérez-Rey, E. Abarca-Morales, V.A. García-Ramírez, V.A. Basiuk, E.V. Basiuk, RSC. Adv. 2018, 8, 15253-15265.

[149] F. Samadaei, M. Salami-Kalajahi, H. Roghani-Mamaqani, M. Banaei, RSC. Adv. 2015, 5, 71835-71843.

[150] Y. Lin, Y. Liao, Z. Chen, J.W. Connell, Mater. Res. Lett. 2017, 5, 209234.

[151] K. Lee, Y. Yoon, Y. Cho, S.M. Lee, Y. Shin, H. Lee, H. Lee, ACS. Nano 2016, 10, 6799-6807.

[152] Y. Zhu, S. Murali, M.D. Stoller, K.J. Ganesh, W. Cai, P.J. Ferreira, A. Pirkle, R.M. Wallace, K.A. Cychosz, M. Thommes, D. Su, E.A. Stach, R.S. Ruoff, Sci. 2011, 332, 1537-1541.

[153] M.A. Worsley, S.O. Kucheyev, H.E. Mason, M.D. Merrill, B.P. Mayer, J. Lewicki, C.A. Valdez, M.E. Suss, M. Stadermann, P.J. Pauzauskie, J.H Satcher, J. Biener, T.F. Baumann, Chem. Commun. 2012, 48, 8428.

[154] L. Mahmoudian, A. Rashidi, H. Dehghani, R. Rahighi, Chem. Eng. J. 2016, 304, 784-792.

[155] J. Zhao, Y. Jiang, H. Fan, M. Liu, O. Zhuo, X. Wang, Q. Wu, L. Yang, Y. Ma, Z. Hu, Adv. Mater. 2017, 29, 1604569.

[156] L. Zhang, F. Zhang, X. Yang, G. Long, Y. Wu, T. Zhang, K. Leng, Y. Huang, Y. Ma, A. Yu, Y. Chen, Sci. Rep. 2013, 3, 1408.

[157] A. lakunkov, V. Skrypnychuk, A. Nordenström, E.A. Shilayeva, M. Korobov, M. Prodana, M. Enachescu, S.H. Larsson, A. V.Talyzin, Phys. Chem. Chem. Phys. 2019, 21, 17901-17912.

[158] S. Chowdhury, R. Balasubramanian, Ind. Eng. Chem. Res. 2016, 55, 7906-7916.

[159] T. Szabo, P. Maroni, I. Szilagyi, Carbon 2020, 160, 145-155.

[160] L. Zhou, Z. Yang, J. Yang, Y. Wu, D. Wei, Chem. Phys. Lett. 2017, 677, 7-12.

[161] W. Li, S. Gao, L. Wu, S. Qiu, Y. Guo, X. Geng, M. Chen, S. Liao, C. Zhu, Y. Gong, M. Long, J. Xu, X. Wei, M. Sun, L. Liu, Sci. Rep. 2013, 3, 2125

[162] L. Shi, K. Chen, R. Du, A. Bachmatiuk, M.H. Rümmeli, K. Xie, Y. Huang, Y. Zhang, Z. Liu, J. Am. Chem. Soc. 2016, 138, 6360-6363.
[163] Z.-Y. Sui, Y. Cui, J.-H. Zhu, B.-H. Han, ACS Appl. Mater. Interfaces 2013, 5, 9172-9179.

[164] R. Kumar, V.M. Suresh, T.K. Maji, C.N.R. Rao, Chem. Commun. 2014, 50, 2015-2017.

[165] K.-K. Liu, B. Jin, L.-Y. Meng, Polymers 2018, 11, 40.

[166] P.M. Sudeep, T.N. Narayanan, A. Ganesan, M.M. Shaijumon, H. Yang, S. Ozden, P.K. Patra, M. Pasquali, R. Vajtai, S. Ganguli, A.K. Roy, M.R. Anantharaman, P.M. Ajayan, ACS. Nano 2013, 7, 7034-7040.

[167] D.K. Singh, V. Kumar, S. Mohan, S.H. Hasan, J. Chem. Eng. Data 2017, $62,1732-1742$.

[168] R. Kanchanapally, B.P. Viraka Nellore, S.S. Sinha, F. Pedraza, S.J. Jones, A. Pramanik, S.R. Chavva, C. Tchounwou, Y. Shi, A. Vangara, D. Sardar, P.C. Ray, RSC. Adv. 2015, 5, 18881-18887.

[169] Y. Wang, C. Guan, K. Wang, C.X. Guo, C.M. Li, J. Chem. Eng. Data 2011, 56, 642-645.

[170] Z. Zhang, F. Li, X. Ji, J. Chen, G. Yang, L.A. Lucia, Bioresources 2019, 14, 7001-7014.

[171] N. Kostoglou, G. Constantinides, G. Charalambopoulou, T. Steriotis, K. Polychronopoulou, Y. Li, K. Liao, V. Ryzhkov, C. Mitterer, C. Rebholz, Thin Solid Films 2015, 596, 242-249.

[172] L. Liu, K.P. Annamalai, Y. Tao, New Carbon Mater. 2016, 31, 336-342.

[173] S. Zhang, G. Liu, Y. Gao, Q. Yue, B. Gao, X. Xu, W. Jiang, Sci. Total Environ. 2019, 694, 133671.

[174] Y. Liu, B. Sajjadi, W.-Y. Chen, R. Chatterjee, Fuel 2019, 247, 10-18.

[175] A.I. Pruna, A.C. Cárcel, A. Benedito, E. Giménez, Nanomaterials 2019, 9, 350.

[176] L. Jiang, Y. Liu, S. Liu, X. Hu, G. Zeng, X. Hu, S. Liu, S. Liu, B. Huang, M. Li, Chem. Eng. J. 2017, 308, 597-605.

[177] J. Wang, Z. Shi, J. Fan, Y. Ge, J. Yin, G. Hu, J. Mater. Chem. 2012, 22, 22459.

[178] C. Chen, X. Zhu, B. Chen, Chem. Eng. J. 2018, 354, 896-904.

[179] E. Platero, M.E. Fernandez, P.R. Bonelli, A.L. Cukierman, J. Colloid. Interface. Sci. 2017, 491, 1-12.

[180] A. Pruna, A.C. Cárcel, A. Barjola, A. Benedito, E. Giménez, Nanomaterials 2019, 9, 1077

[181] H. Bi, K. Yin, X. Xie, Y. Zhou, N. Wan, F. Xu, R.S. Ruoff, Adv. Mater. 2012, 24, 5124-5129.

[182] W. Wang, Y. Wu, Z. Jiang, M. Wang, Q. Wu, X. Zhou, X. Ge, Appl. Surf. Sci. 2018, 427, 1144-1151.

[183] H. Jo, H. Noh, M. Kaviany, J.M. Kim, M.H. Kim, H.S. Ahn, Carbon 2015 81, 357-366.

[184] R. Du, X. Tian, J. Yao, Y. Sun, J. Jin, Y. Zhang, Y. Liu, Diam. Relat. Mater. 2016, 70, 186-193.

[185] L. Ren, K.N. Hui, K. S. Hui, Y. Liu, X. Qi, J. Zhong, J. Yang, Sci. Rep. 2015, 5, 14229.

[186] R. Kumar, J.H. Oh, H.J. Kim, J.H. Jung, C.H. Jung, W.G. Hong, I.K. Oh ACS nano 2015, 9, 7343-7351.

[187] T. Wang, J. Li, Y. Zhang, F. Liu, B. Zhang, Y. Wang, C.P. Wong, Chem. Eur. J. 2019, 25, 6378-6384.

[188] J. Zhao, W.H. Li, H.Z. Xu, L.S. Sun, C.Q. Li, F.Q. Liu, RSC Adv. 2016, 675, 70972-70977. 


\section{Entry for the Table of Contents}

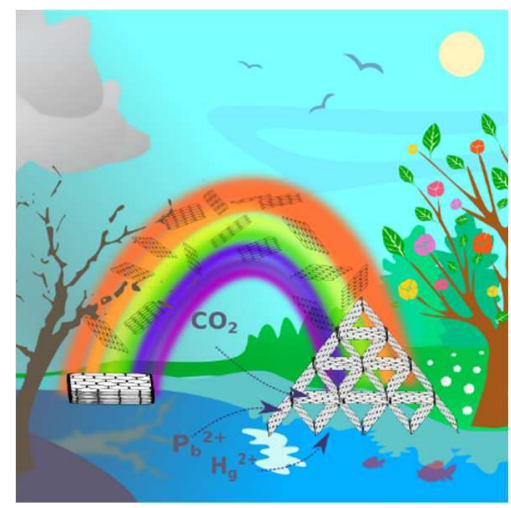

Assembly of nanomaterials such as graphene into 3D hierarchized nanostructures is definitely of great interest for a wide range of environmental applications. The idea of the present research is to transfer the properties of a super nanomaterial to a macroscopic material which should have its own properties multiplied.

Twitter:

@labo_IJL

@USMOfficial1969 